\title{
Vibration Transmission Characteristics and Detection Method of Bilateral Chain Drive of Multicylinders
}

\author{
Yu Li, Zhong Tang ${ }^{D}$, Ben Zhang, and Meilin Wang \\ Key Laboratory of Modern Agricultural Equipment and Technology of Ministry of Education, Jiangsu University, Zhenjiang, \\ Jiangsu 212013, China
}

Correspondence should be addressed to Zhong Tang; tangzhong2012@126.com

Received 7 February 2021; Accepted 19 May 2021; Published 29 May 2021

Academic Editor: Yong Zhang

Copyright () $2021 \mathrm{Yu} \mathrm{Li}$ et al. This is an open access article distributed under the Creative Commons Attribution License, which permits unrestricted use, distribution, and reproduction in any medium, provided the original work is properly cited.

\begin{abstract}
The transmission modes of multiple rotating parts on the combine harvester are complex and diverse, and the excitation vibrations are coupled with each other, which makes it difficult to dynamically balance the parallel rotating bodies on-site. In order to obtain the influence of the multicylinder transmission system on the vibration response and transmission characteristics of the whole machine providing an experimental basis for the overall balance of the multicylinder system, this paper tested and analyzed the vibration response and shaft vibration state of the system under different transmission modes. On this basis, the influence of chain drive and different transmission modes on the vibration characteristics of the multicylinder was analyzed. Through the tests of the vibration response of the multicylinder frame, the main transfer path of the vibration of each excitation source was analyzed. The results showed that the transmission chain and transmission mode would affect the stiffness, damping, and vibration response of the cylinder fundamental frequency of the chain transmission system on both sides of the multicylinder. The contribution rate of different transmission modes and rotation speeds to the vibration at the fundamental frequency of the multicylinder was $5 \%$ $30 \%$, which would also cause the deflection angle of the roller axis track to change from $1^{\circ}$ to $5^{\circ}$. The frame was the main path of vibration transmission of bilateral chain drive of the multicylinder system, and the vibration transmission efficiency of the frame under different frequencies can reach more than $80 \%$. In addition, the vibration response of each cylinder would also be transmitted to each bearing seat position of the multicylinder through the frame.
\end{abstract}

\section{Introduction}

As complex agricultural machinery, the combine harvester can complete operations such as harvesting, threshing, separating, and cleaning crops at one time $[1,2]$. The multifunctional operation characteristics of the combine harvester are of great significance for improving labor productivity [3]. However, the combine harvester has many working parts and complex and diverse power transmission modes, which will cause the whole machine to have problems such as large vibration and poor stability in the actual working process, restricting the development of the combine harvester to the high-end direction seriously $[4,5]$. Due to the large distance between the working parts of the combine harvester and the great differences in their working characteristics, the power transmission mode between them is mainly chain transmission [6]. The meshing effect of the transmission chain often has a large impact force and lateral vibration. In addition, due to the polygon effect of the chain transmission, the chain transmission has an uneven working speed [7].

The research studies on the kinematic characteristics of chain/belt transmission were relatively early. Čepon et al. analyzed the mathematical model of the belt transmission process and simplified the transmission belt into a belt transmission mode with a plane beam element and an absolute node coordinate formula. The damping mechanism was introduced into the belt drive model to establish the relevant stiffness and damping matrix, and the transmission characteristics of the two models were compared and analyzed to verify the applicability and feasibility of the model $[8,9]$. Due to the polygon effect in the transmission process 
of the transmission chain, its vibration state is more complicated $[10,11]$. Due to the influence of polygonal effect and meshing impact effect on the synchronization and uniformity of the transmission system, Wang et al. took the chain drive in the timing mechanism of gasoline engine as the research object, developing a new sprocket tooth profile that can reduce the polygon effect and meshing influence at high speeds [12]. In order to further improve the mathematical model of the roller chain, Pereira et al. modeled the roller chain transmission as a constrained power system. The chain drive system was simplified to a model composed of a large number of rigid bodies, chain links, rollers, and sprockets, and the dynamic simulation analysis was performed on it. On this basis, its motion characteristics during meshing were solved and analyzed [13]. Fuglede and Thomsen approximated the motion model of the roller chain and proposed an approximate kinematics solution for the roller chain drive with a four-bar linkage mechanism. On this basis, the mathematical model of chain kinematics was compared with the simulation results, and the results showed that it had good consistency with the actual motion characteristics $[14,15]$.

The transmission chain not only plays the role of power transmission but also causes the mutual coupling of the various working parts in the system. This makes each part of the system no longer a separate individual, but a system composed of a transmission rotating body, in which their motion states will affect each other. Zhang et al. took the rotor system of a centrifugal compressor as the research object and analyzed the vibration characteristics of a fiveshaft gear parallel rotor system. By analyzing the influence of external load on the stiffness and damping of the bearing in the system, the critical speed of the rotor system was solved and the resonance characteristics of the system were analyzed [16]. Apart from this, studies had shown that the coupled vibration of the rotor and the bearing inside the transmission system would also affect the motion state of the rotor. Yu et al. took a typical electric vehicle driven by a fourphase 8/6-pole switched reluctance motor without a reduction mechanism as an example. Based on the analysis of motor excitation force and bearing nonlinear force, a nonlinear dynamics model of electric vehicle with the inwheel motor drive system was established [17]. Xiang and Gao studied the torsional vibration coupling response of the gear-rotor-bearing system and analyzed the meshing stiffness that changes with time. On this basis, the dynamic characteristics of the transmission system were analyzed [18]. Saxena et al. proved that the contact of gear pairs would seriously affect the dynamic characteristics of the system through experiments. On this basis, the frequency response function results of the separated and coupled gear-rotor system were solved and analyzed, upon which the influence of gear contact on the natural frequency of the system was found [19]. The above research studies are mainly based on the gear transmission system, and its influence on the vibration response of the system was tested and theoretically analyzed. However, there is little research on the influence of chain or belt transmission on the vibration characteristics of the system.
Due to the lateral vibration and polygon effect of the transmission chain during the movement, the transmission system vibrates greatly during the power transmission process, which may affect the vibration response of various parts of the system. For a vibration system, the vibration of each part of the system is the result of the comprehensive action of each vibration source in the system at that position. Therefore, it is particularly important to study the vibration characteristics of the system and the vibration transfer path under multisource excitation. Yang et al. took viscoelastic beams as the research object, using Newton's second law, Kelvin's structural relationship, and Lagrangian strain to obtain a nonlinear partial differential equation that controls the lateral vibration of the beam. On this basis, the axial vibration response under multifrequency excitation was solved [20]. Wang et al. developed an improved calculation mode for predicting gearbox vibration and noise, which took into account the flexibility of the shaft. Based on the finite element mode (FEM), a coupling dynamics model of the spur gear-bearing system was established, and the vibration amplitude and excitation frequency of the system under different loads were solved and analyzed [21]. Briend et al. took turbochargers as the research object and performed excitations under single-frequency and multifrequency parameters, respectively. Through simple and combined sinusoidal support rotation or unbalanced rotating mass combined with sinusoidal support translation to excite the rotor, the vibration characteristics of the rotor system under multisource excitation were analyzed [22]. The identification of the vibration characteristics under multisource excitation and the identification of the vibration source is certainly important for system vibration reduction, but the solution and analysis of the vibration transfer path is also an important aspect of system vibration reduction. Especially in the aviation field, there are many research studies on the mechanism of vibration transmission.

Since the rotating bodies and the transmission between them are built on the supporting frame, the vibration of the rotors will also be transmitted through the supporting frame and affect the vibration characteristics of other rotor systems. In order to study the transmission characteristics of the rotor system through the supporting shell, Yang et al. analyzed the vibration characteristics of the aeroengine rotor shell and proposed the vibration transmission mechanism from the internal excitation source to the shell. On this basis, the vibration propagation characteristics were quantitatively evaluated [23]. Wu et al. focused on the control moment gyroscope (CMG) in spacecraft, established a related mathematical model to analyze the transmission mechanism of CMG microvibration. Through modal analysis, frequency response analysis, and dynamic and static unbalanced excitation analysis, the parameters of the system microvibration transmission mode were identified [24]. Hou et al. took the shell of an aeroengine dualrotor system as the research object and modeled the vibration signal generated by the rotor excitation and under the combined action of multiple paths in the system. On this basis, the characteristics of the vibration signal of each measuring point were extracted and analyzed [25]. 
Considering the influence of multiple transfer paths, the vibration waveform and frequency spectrum characteristics with or without friction signals were derived and simulated. Vibration transmission characteristics have also been studied in the fields of machinery and vehicles. Zeng et al. took planetary gear transmissions as the research object and analyzed the vibration transfer paths. Since the excitation of the system was a time-varying meshing force, the transfer path of its excitation was a time-varying system. In response to this problem, a spatiotemporal model and signal processing mode for time-varying problems was proposed [26]. In order to improve the ride comfort of the vehicle, the main vibration transfer path of the truck was analyzed. According to the structural characteristics of car body modal deformation, a multipoint iterative analysis mode (MIAM) was proposed [27]. For the combine harvester, there are many vibration sources in the system; as a result, its vibration state and the transfer path are complex and diverse. Chen et al. took rice combine harvester as the research object. Based on the multisource excitation of the combine harvester, the vibration response of the combine harvester frame under the multisource excitation was deduced, and the dynamic model of the combine harvester frame as a rigid body with 7 degrees of freedom was established [28]. In order to reduce the vibration response of the combine harvester and improve its working stability, it is necessary to analyze the vibration characteristics of each main part of the combine harvester to find the source of the main vibration and the transfer path. On this basis, the vibration source of the combine harvester is damped and the vibration is isolated on the vibration transfer path to achieve the purpose of reducing the vibration of the vibration system.

Due to the coupling of the parallel multicylinder drive system on the combine harvester and the complexity and diversity of the transfer path, the on-site dynamic balance of the parallel rotating body was quite difficult. This paper tested and analyzed the coupled vibration response of the system under different transmission modes of multiple cylinders of the combine harvester. On this basis, the vibration transfer path of the excitation source and the contribution to the vibration of the main excitation object were analyzed, which provided an important experimental basis for the proposal of the balance method under the coupling effect of the parallel multicylinder system on the combine harvester.

\section{Material and Modes}

2.1. Multicylinder Bilateral Transmission Structure and Model. As complex agricultural machinery, the combine harvester can complete harvesting, threshing, separation, cleaning, and other operations at one time [29]. Its powerful and comprehensive functions will inevitably lead to more working parts and complex transmission. Due to the unique working characteristics of the combine harvester, multiple rotating parts on it can only be driven by belt or chain for power transmission. The drive system on the side of the combine harvester is shown in Figure 1.

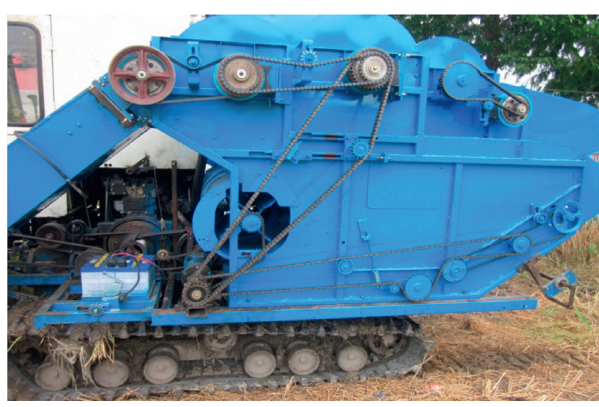

FIGURE 1: Multicylinder chain drive on the combine harvester.

The working parts of the combine harvester are basically rotating parts, such as the engine, the conveying trough, the threshing cylinder, and the fan, which are all transmitted through the transmission chain. The power transmission system and transmission mode of the combine harvester are shown in Figure 2. When these rotating parts appear unbalanced vibration, it will inevitably cause the vibration of the whole machine to become larger, which affects its working stability. Due to the existence of the transmission mode, the rotating bodies will also be coupled with each other, which also leads to more complex and diverse vibration transfer paths [30], leading to great difficulties in the overall balance of the multicylinder system on the combine harvester.

\subsection{Vibration Test Model of Multicylinder Bilateral} Transmission. In order to study the vibration characteristics and transmission characteristics of multiple cylinders in parallel on the combine harvester in different transmission modes, a multicylinder vibration test bench was sued whose specific structure is shown in Figure 3.

The experimental platform consisted of a three-layer structure, and the motor was placed on the bottom layer. An eddy current sensor was installed on the motor output shaft, to which a digital display controller was connected to display the motor speed in real time. Three cylinders with the same structure were placed in the middle. In addition, two sprockets of different sizes were installed at both ends of each cylinder to test the difference in vibration characteristics of multiple cylinders when they were driven on one side and two sides. There were small holes of the same size on the two ends of each cylinder, which were used to add unbalanced masses on the cylinder to change the movement of the cylinder itself. On this basis, the difference of the vibration characteristics of each cylinder under different motion states was analyzed. During the tests, the vibration characteristics under four representative working conditions were selected for testing and analysis, mainly including single-cylinder vibration characteristic tests, two-cylinder unilateral transmission, two-cylinder bilateral transmission, three-cylinder unilateral transmission, and three-cylinder bilateral transmission vibration characteristic tests. The multicylinder bilateral transmission modes are shown in Figure 4.

There were three main sources of excitation in the multicylinder system. The first excitation source was the 


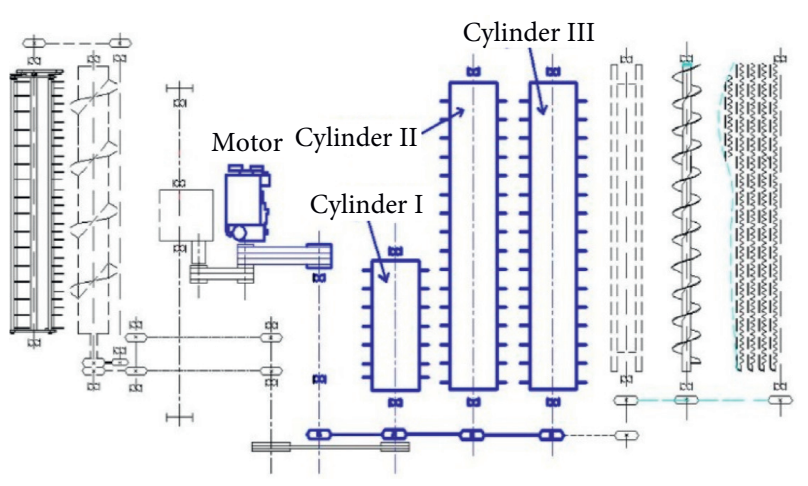

FIGURE 2: Multicylinder power transmission route on the combine harvester.

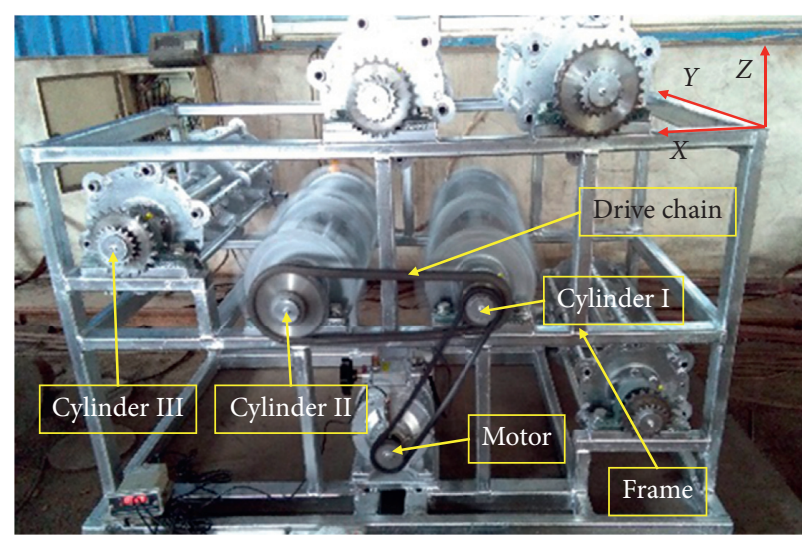

FIGURE 3: Multicylinder vibration test physical model.

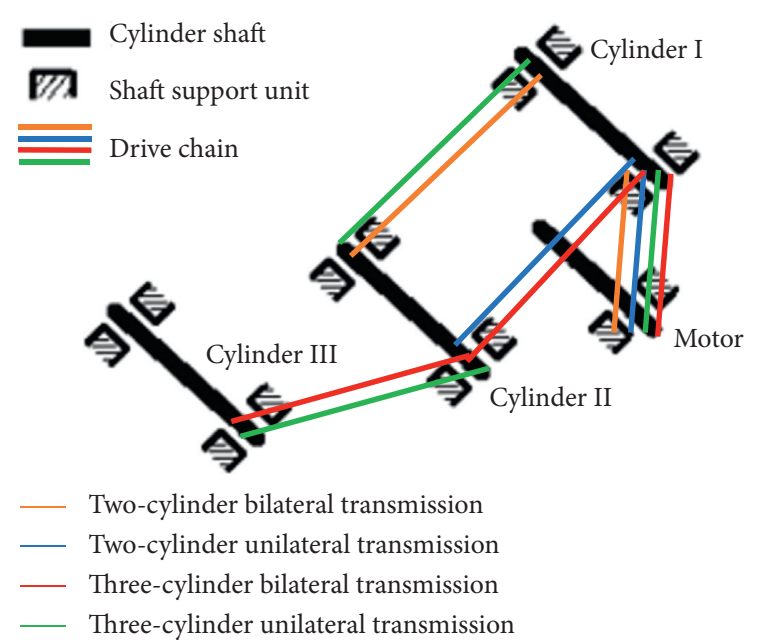

FIGURE 4: Schematic diagram of multicylinder transmission mode.

excitation of the motor to the entire system. Since the transmission ratio between the cylinder I and the motor were 1 , the excitation frequencies of the two had the same part. The second excitation source was the vibration response stimulated by the unbalance of the cylinder itself. The excitation frequency was generally the fundamental frequency of the cylinder and its multiples. The third excitation source was the transmission chain. Due to the polygon effect in the meshing process of the chain and the sprocket, the chain had intermittent motion during the transmission of power. The target of the excitation source mainly included three. The first was the cylinder shaft; the second was the bearing seat; the third was the frame. In order to analyze the main vibration causes of each acting object, it was necessary to analyze the vibration characteristics of each acting object and the transmission characteristics between them, so as to find the reasons that cause their respective vibrations. On this basis, the vibration of the entire system was reduced at the source, thereby improving the stability and reliability of the whole machine.

In order to test the impact of the three main sources of excitation in the system on the vibration response of the bearing seats, the vibration characteristics of the bearing seats were first tested. Since the bearing seat positions were the first transmission position of the cylinder unbalanced vibration response in the transmission process, the vibration of the bearing seats reflected the vibration characteristics of the unbalanced response on the cylinder. In order to analyze the influence of the transmission chain on the motion state of the rotating shaft, preliminary tests and analysis of the vibration response of the bearing seat can be carried out, and then the displacement signal of the shaft center trajectory of the rotating shaft can be further analyzed and verified.

\subsection{Multicylinder Bilateral Transmission Vibration Test} Method. The vibration test instruments used in the test were the vibration test software produced by China Donghua Vibration Testing Co., Ltd. and the corresponding vibration test acquisition analyzer DH5902. The vibration test acquisition and analysis system used in the experiment are shown in Figure 5, including a supporting computer and a signal acquisition instrument. The acquisition instrument had 38 terminals, 2 of which were speed channels, and the remaining 36 were vibration test channels. The instrument was equipped with a wireless module, which can realize realtime data transmission of medium and short distances during the tests. It can convert the collected analog signals into digital signals in real time and transmit them to the software for real-time analysis and storage.

The sensors used in the vibration tests were three-way acceleration sensors produced by Yangzhou Xiyuan Electronic Technology Co., Ltd. The three-way acceleration sensors for vibration tests are shown in Figure 6. During the tests, the specific model of the three-way acceleration sensors, the direction of vibration measurement, and the sensitivity of each direction are shown in Table 1.

The direction of each three-way acceleration sensor was the relative coordinate direction, and the installation method of each sensor is shown in Figure 7. The vibration directions measured in the $X, Y$, and $Z$ directions of the three-way acceleration sensor are shown in Table 1 . The vibration directions mentioned in this article were the overall coordinate directions, not the individual sensor directions. The method of the single-cylinder bearing seat vibration 


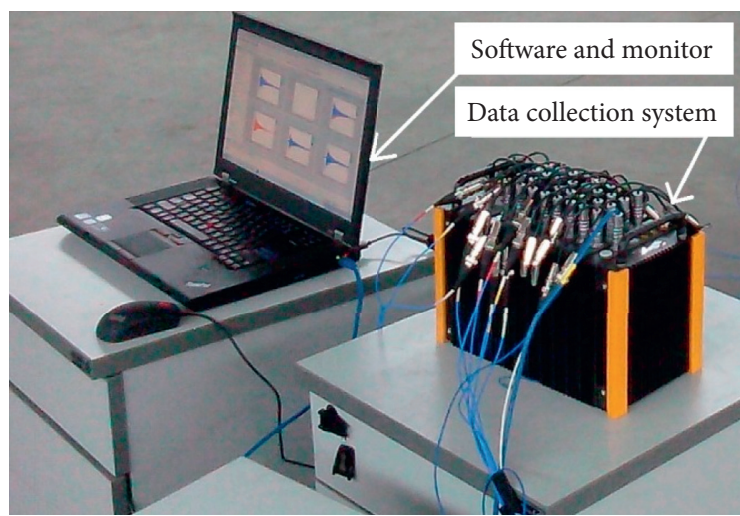

FIgURe 5: Dynamic signal acquisition instrument.

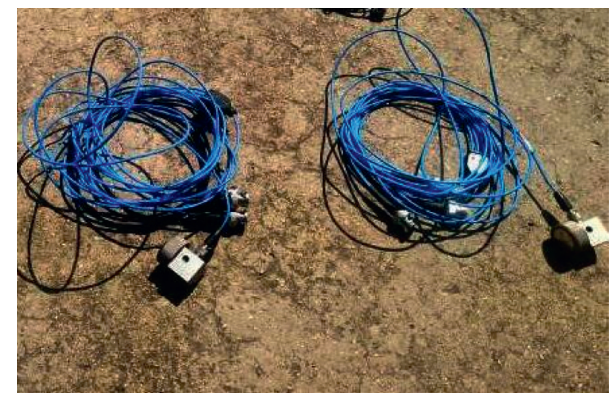

Figure 6: Three-way acceleration sensors for vibration tests.

characteristic test was to arrange acceleration sensors 820614 and 820616 on the bearing seats at both ends of the cylinder, 820614 was installed on the bearing seat in the $Y$ direction of the entire system, and 820616 was installed on the bearing seat on the other side of the cylinder I. The arrangement of the acceleration sensors is shown in Figure 7. The vibration test methods under other transmission modes were the same. There were two main types of vibration characteristics tests for single cylinder; one was to test the vibration characteristics of the bearing seat at different speeds under no load. The second was to apply an unbalanced mass of $127.89 \mathrm{~g}$ in its $0^{\circ}$ phase. The application method of the unbalanced mass in the tests is shown in Figure 7.

During the tests, the rotation speed of each cylinder was from $600 \mathrm{r} / \mathrm{min}$ to $800 \mathrm{r} / \mathrm{min}$, and the rotation speed was increased by $50 \mathrm{r} / \mathrm{min}$ each time. The adjustment started from the low speed first, and the data were collected and stored after the speed was relatively stable. In the actual working process of the cylinders, multiple rotating bodies were often connected in parallel through a transmission chain for continuous transmission, so it was necessary to test and analyze the vibration characteristics of the movement when multiple cylinders were connected through the transmission chain. This article mainly included four working conditions: two-cylinder unilateral transmission, two-cylinder bilateral transmission, three-cylinder unilateral transmission and three-cylinder bilateral transmission. In the actual tests, the connection modes of the transmission system under various working conditions are shown in Figure 8.
In order to analyze the influence of the transmission chain and the transmission mode on the vibration state of the system during the tests, the vibration characteristics of the four transmission modes under different working conditions were tested. The main working conditions during the tests and the movement state of each cylinder are shown in Table 2.

2.4. Frame Transmission Characteristics and Vibration Characteristic Test. Since each rotating shaft in the multicylinder system was connected to the frame through a bearing and a bearing seat, there may be vibration transmission between them through the frame. At the same time, the rotating shafts of the multiple cylinders were also connected to adjacent cylinders through sprockets and transmission chains, and there was also the possibility of transmission of vibration between them through the chain. Therefore, in order to analyze the characteristics of system vibration transmission under two different transfer paths, it was necessary to test and analyze the transmission characteristics of the transmission chain and the frame, respectively. The installation distance between adjacent cylinders was relatively close. Therefore, in the vibration test of the transfer path of the frame, three representative positions were selected, namely, the bearing seat of cylinder I, the support beam in the middle of the two cylinders, and the bearing seat of cylinder II.

The bearing seat of each cylinder was installed on the beam of the frame, and the shortest and most effective path for vibration transmission was through the beam. The vibration on cylinder I can be transmitted to cylinder II through the frame, and at the same time, the vibration of cylinder II can also be transmitted to cylinder I through the frame. In order to compare the amount of vibration of each measuring point in the transmission process, three-way acceleration sensors were installed at these three representative positions for vibration testing. The installation method of the acceleration sensors used in the multicylinder vibration transmission test is shown in Figure 9.

In order to facilitate the analysis of the transmission characteristics of the vibration caused by the imbalance of the cylinder during the tests, $180 \mathrm{~g}$ and $228 \mathrm{~g}$ of unbalanced masses were, respectively, applied to the $0^{\circ}$ phase of the cylinder I and the cylinder II. On this basis, the vibration signal of the frame was tested and analyzed, and the signal components of the frame vibration were analyzed to find the main reason of the frame vibration. In order to facilitate the comparative analysis with the signal measured by the vibration acceleration, the test conditions during the measurement of the frame displacement should be the same as those during the acceleration signal measurement. In the frame vibration test, a total of three measuring points was selected, namely, the bearing seat of cylinder I, the support beam at the middle position of the two cylinders, and the bearing seat of cylinder II. On this basis, the displacement signal of the frame was tested.

In the frame displacement test, the position directly measured on the frame was selected as the main comparison 
TABLE 1: Sensors model and sensitivity in various directions.

\begin{tabular}{|c|c|c|c|c|c|c|c|c|c|}
\hline Number & Model & Direction & Measuring direction & Sensitivity $/ \mathrm{mv} / \mathrm{ms}^{-2}$ & Number & Model & Direction & Measuring direction & Sensitivity $/ \mathrm{mv} / \mathrm{ms}^{-2}$ \\
\hline & & $\mathrm{X}$ & $\mathrm{X}$ & 1.05 & & & $\mathrm{X}$ & $\mathrm{X}$ & 1.02 \\
\hline \multirow[t]{3}{*}{1} & 820614 & $\mathrm{Y}$ & $\mathrm{Y}$ & 1.05 & 4 & 820616 & Y & Y & 1.05 \\
\hline & & Z & Z & 1.03 & & & Z & Z & 1.05 \\
\hline & & $\mathrm{X}$ & $\mathrm{Z}$ & 1.04 & & & $\mathrm{X}$ & $\mathrm{Z}$ & 1.04 \\
\hline \multirow[t]{3}{*}{2} & 820618 & $\mathrm{Y}$ & $\mathrm{Y}$ & 1.05 & 5 & 820617 & $\mathrm{Y}$ & $\mathrm{X}$ & 1.03 \\
\hline & & $\mathrm{Z}$ & $\mathrm{X}$ & 1.05 & & & Z & $\mathrm{Y}$ & 1.04 \\
\hline & & $\mathrm{X}$ & $\mathrm{Z}$ & 1.04 & & & $\mathrm{X}$ & Z & 1.04 \\
\hline \multirow[t]{2}{*}{3} & 820615 & $\mathrm{Y}$ & $\mathrm{X}$ & 1.06 & 6 & 820619 & $\mathrm{Y}$ & $\mathrm{Y}$ & 1.04 \\
\hline & & $\mathrm{Z}$ & $\mathrm{Y}$ & 1.05 & & & Z & $\mathrm{X}$ & 1.05 \\
\hline
\end{tabular}

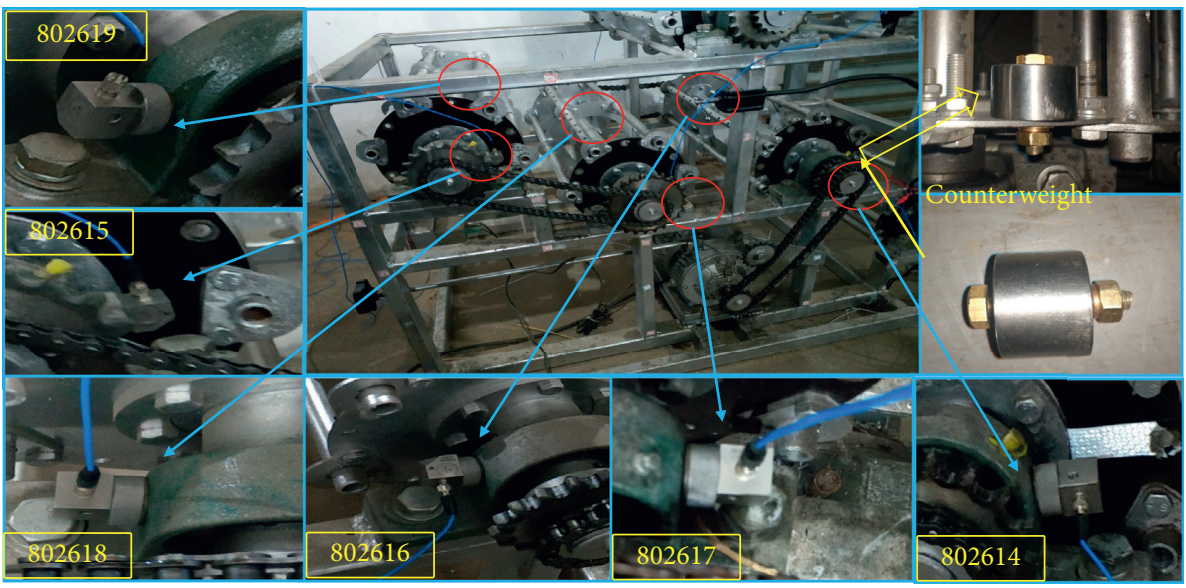

FIGURE 7: Layout of the acceleration sensors and application of the counterweight.

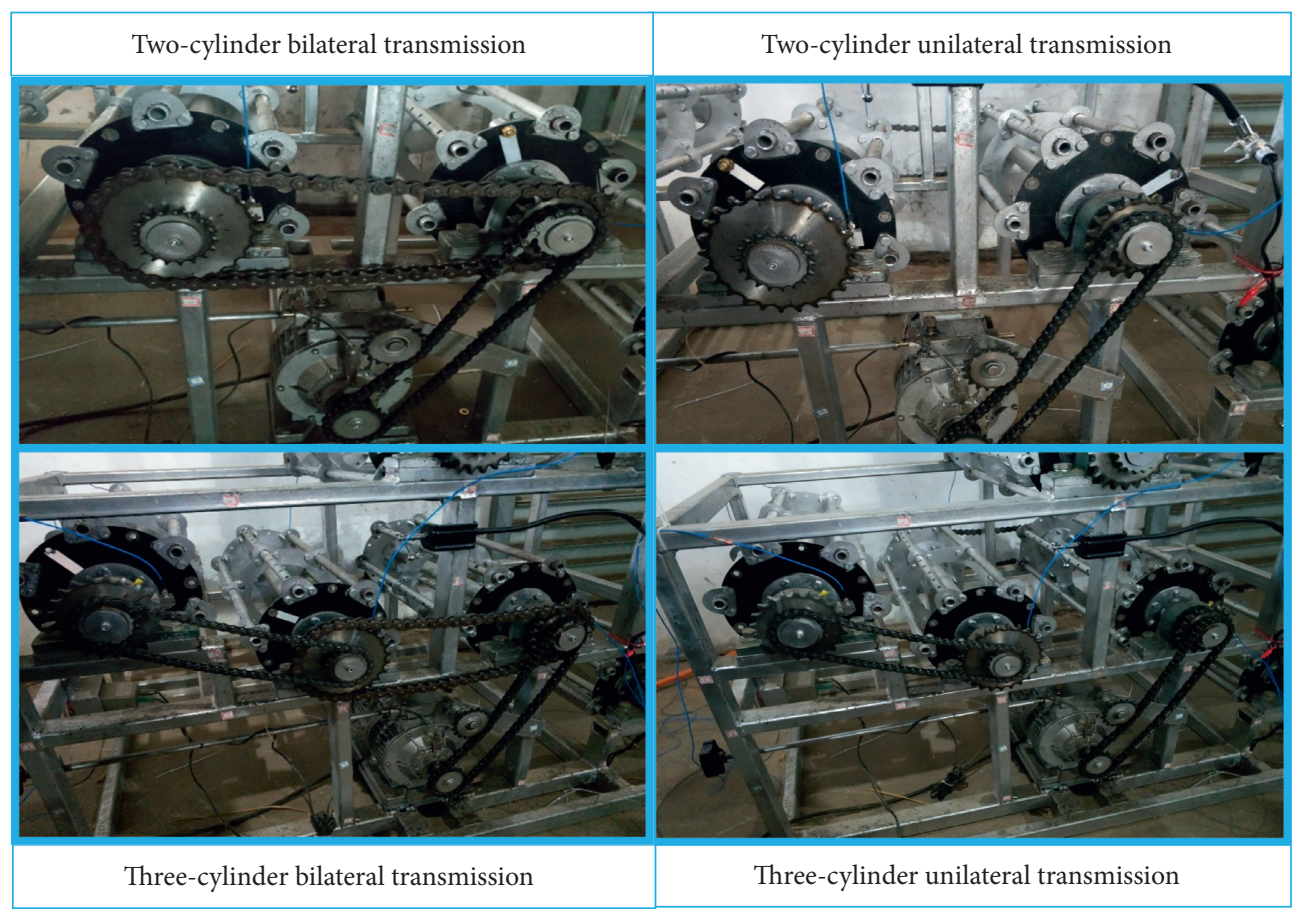

Figure 8: The connection modes of the transmission system. 
TABLE 2: The main working conditions during the tests and the movement state of each cylinder.

\begin{tabular}{|c|c|c|c|c|}
\hline Working condition & $\begin{array}{c}\text { Cylinder I counterweight } \\
(\mathrm{g})\end{array}$ & $\begin{array}{l}\text { Cylinder II counterweight } \\
\text { (g) }\end{array}$ & $\begin{array}{c}\text { Cylinder III counterweight } \\
(\mathrm{g})\end{array}$ & $\begin{array}{l}\text { Motor speed } \\
(r / \mathrm{min})\end{array}$ \\
\hline \multirow{2}{*}{ Single-cylinder transmission } & 0 & - & - & \multirow{2}{*}{$\begin{array}{c}600,650,700,750, \\
800\end{array}$} \\
\hline & 127.9 & - & - & \\
\hline \multirow{3}{*}{$\begin{array}{l}\text { Two-cylinder unilateral } \\
\text { transmission }\end{array}$} & 0 & 0 & - & \multirow{3}{*}{$\begin{array}{c}600,650,700,750, \\
800\end{array}$} \\
\hline & 127.9 & 0 & - & \\
\hline & 0 & 227.89 & - & \\
\hline \multirow{4}{*}{$\begin{array}{l}\text { Two-cylinder bilateral } \\
\text { transmission }\end{array}$} & 127.89 & 0 & - & \multirow{4}{*}{$\begin{array}{c}600,650,700,750, \\
800\end{array}$} \\
\hline & 0 & 227.89 & - & \\
\hline & 0 & 0 & - & \\
\hline & 127.89 & 0 & 0 & \\
\hline \multirow{4}{*}{$\begin{array}{l}\text { Three-cylinder unilateral } \\
\text { transmission }\end{array}$} & 0 & 227.89 & 0 & \multirow{4}{*}{$\begin{array}{c}600,650,700,750, \\
800\end{array}$} \\
\hline & 0 & 0 & 227.89 & \\
\hline & 0 & 0 & 0 & \\
\hline & 0 & 0 & 0 & \\
\hline \multirow{3}{*}{$\begin{array}{l}\text { Three-cylinder bilateral } \\
\text { transmission }\end{array}$} & 127.89 & 0 & 0 & \multirow{3}{*}{$\begin{array}{c}600,650,700,750, \\
800\end{array}$} \\
\hline & 0 & 227.89 & 0 & \\
\hline & 0 & 0 & 227.89 & \\
\hline
\end{tabular}

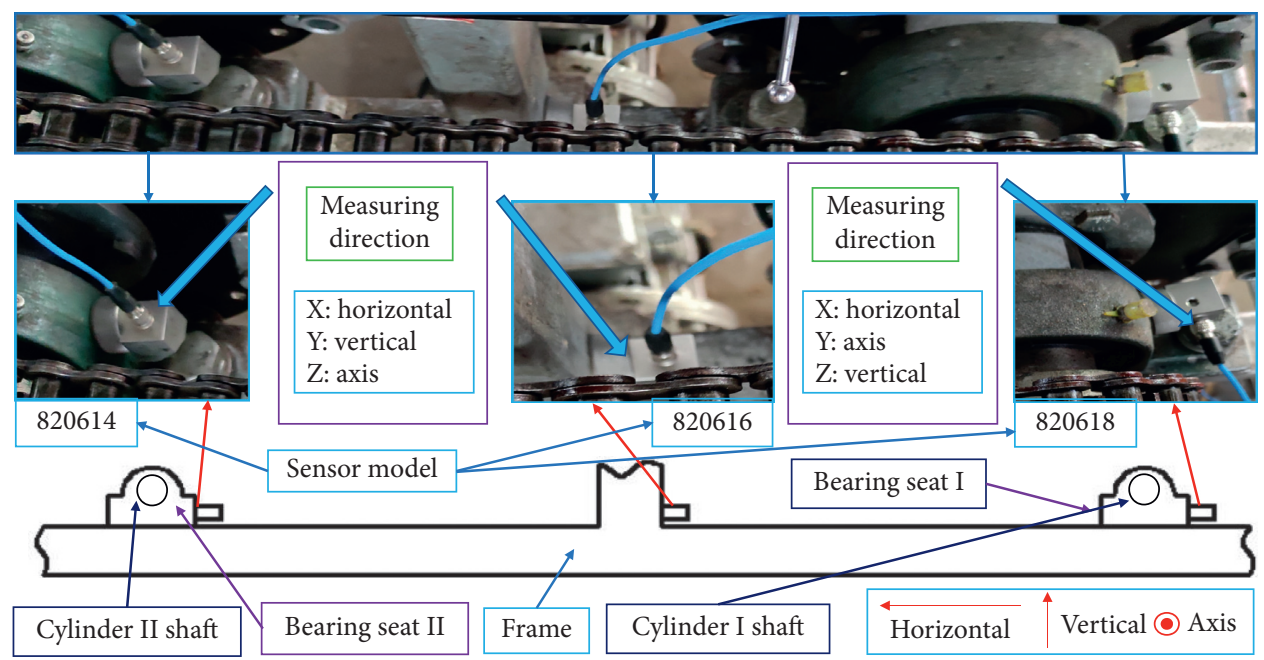

FIGURE 9: Installation method of acceleration sensors for vibration transmission test on the frame.

point of the vibration signal. The vibration signal measured at the acceleration of the support beam at the middle position of the two cylinders was the vibration response of the actual acceleration of the frame, so the signal result at this position was more intuitive and comparable. The sensor used was a 5 E105 eddy current sensor produced by Donghua Vibration Testing Co., Ltd., with a sensitivity of $1300 \mathrm{mV} /$ $\mathrm{mm}$ and a range of $6 \mathrm{~mm}$. The eddy current displacement sensor was used to test the displacement in three directions on the support beam in the middle of the two cylinders. The installation method of the eddy current displacement sensor on the frame is shown in Figure 10.

\subsection{Multicylinder Shaft End Vibration Characteristic Test Plan}

2.5.1. Instruments and Test Methods Used in the Test. In this experiment, the axis trajectory measurement method used in engineering was adopted to test the state of the rotating shaft, and the axis trajectory of the rotating shaft was measured by two eddy current sensors at $90^{\circ}$ to each other. In addition, the displacement signal of any one of the eddy current sensors can also be processed and analyzed to obtain the motion state of the shaft. The measuring principle of the axis trajectory of the eddy current sensor and the installation method of the eddy current sensor during the test are shown in Figure 11.

In order to study the influence of the transmission chain and transmission mode on the vibration state of the shaft, the test conditions were mainly divided into four types, namely, two-cylinder unilateral transmission, two-cylinder bilateral transmission, three-cylinder unilateral transmission, and three-cylinder bilateral transmission. The tests were mainly the rotation of three cylinders and two cylinders. Therefore, it was necessary to compare and analyze the vibration signals in each motion state. Whether it was the case of two cylinders or three cylinders, both cylinder I and 


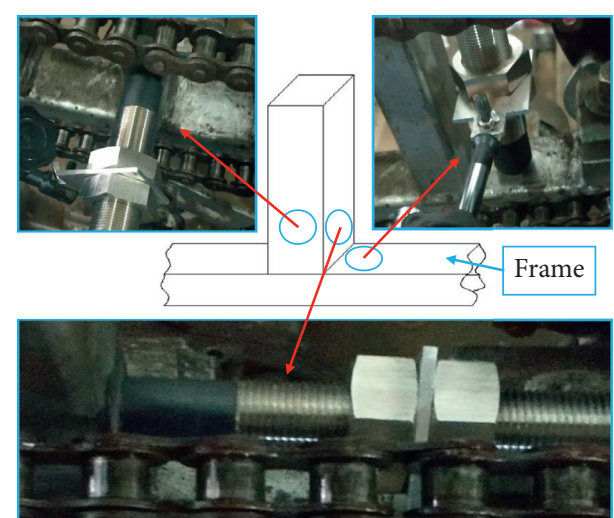

FIgURE 10: Installation method of eddy current displacement sensor on the frame.

cylinder II participate in the entire movement process. Therefore, in order to facilitate the comparison and analysis of the difference in the vibration characteristics of the shaft end under various working conditions, the main measurement positions during the test were the shaft ends of cylinder I and cylinder II.

\subsubsection{Test Method for Vibration of the Drive Shaft End of the} Two-Cylinder Parallel Chain. In order to compare and analyze the vibration results of the bearing seat, the working conditions of the double-cylinder shaft end vibration tests were the same as the vibration tests of the bearing seat. It mainly included two-cylinder unilateral transmission and two-cylinder bilateral transmission. The schematic diagram of the specific connection mode is shown in Figure 8. Before the tests, the axis track of the cylinder I was tested when it was working alone, and an unbalanced mass of $227.89 \mathrm{~g}$ was applied to its $0^{\circ}$ phase as the reference group for the vibration characteristic tests of the cylinder shaft end. On this basis, the two-cylinder unilateral and bilateral transmission characteristic tests were carried out.

The tests were mainly divided into three working conditions. The first test condition was to apply an unbalanced mass with a mass of $227.89 \mathrm{~g}$ to the $120^{\circ}$ phase of cylinder I and test the axis trajectory of the rotating shaft of cylinder I at different speeds. The rotation speed was from $600 \mathrm{r} / \mathrm{min}$ to 800 ( $\mathrm{min}$ ), and each time it was increased by $50 \mathrm{r} / \mathrm{min}$. Based on this, the influence of the speed change on the vibration response of the shaft end was analyzed. The second test condition was that an unbalanced mass with a mass of $278.89 \mathrm{~g}$ was applied to the $120^{\circ}$ phase of the cylinder II, and the vibration states of the cylinder II shaft at different speeds were also tested. The third test condition was to apply unbalanced masses on both cylinders I and II, and the applied masses on each cylinder were the same as before. The loading method of the unbalanced mass was the same as the installation method of the previous bearing seat vibration characteristic tests. In order to facilitate the comparative analysis and feature extraction of the results, the installation plane was also exactly the same as before.
2.5.3. Test Method for Vibration of the Drive Shaft End of the Three-Cylinder Parallel Chain. As the combine harvester often has multiple rotating parts connected by a transmission chain in the actual work process, when multiple parts worked, the vibration of the whole machine increased significantly. Therefore, it is particularly important to test the motion state of the rotating shaft when multiple rotating bodies are connected. Due to the complex and diverse delivery methods in the actual process, it is impossible to analyze all delivery situations one by one. This paper selected the transmission characteristics of the most representative multicylinder drive modes for testing and analysis, and on this basis, it studied the vibration response characteristics and vibration transmission characteristics of the multicylinder parallel chain drive.

The tests were mainly divided into two typical working conditions, namely, three-cylinder unilateral transmission and three-cylinder bilateral transmission. Since the test results will be compared and analyzed with the motion state of the shaft ends of the two-cylinder multilateral transmission, it mainly tested the vibration state of the shaft ends of cylinder I and cylinder II. The working conditions in the three-cylinder unilateral transmission tests and the three-cylinder bilateral transmission tests were exactly the same, mainly divided into three working conditions. The test methods under the three working conditions were exactly the same as the two-cylinder multilateral transmission. In order to compare analysis of the test results and improve the reliability of the test results, the sensor positions on the cylinders I and II did not change in the vibration characteristics of the three-cylinder multilateral transmission shaft end.

\section{Result and Discussion}

\subsection{Analysis of Vibration Characteristics of Multicylinder Bearing Seat in Parallel}

3.1.1. Vibration Characteristics of Bearing Seat of Single/DoubleCylinder Chain Drive. When the threshing cylinders was unbalanced in the working process, the vibration generated by it would be transmitted to other parts of the system through the position of the bearing seat, so the vibration response of the position of the bearing seat can reflect the state of the cylinder during the movement [31]. Since the bearing seat was installed on the frame, the vibration response at this location was very complicated, not only the vibration caused by the unbalance of the cylinder, but also the frequency components of other vibration sources. The vibration of the whole system was mainly divided into three directions. The vibration response caused by the lateral vibration of the chain and the unbalanced response of the cylinder was mainly concentrated in the horizontal and vertical directions of the system, so the influence of axial vibration was not considered for the time being. Take the vibration data of the acceleration sensor in the horizontal direction when the rotation speed of the cylinder I was $600 \mathrm{r} /$ min after $127.89 \mathrm{~g}$ unbalanced mass was applied to the $0^{\circ}$ phase as an example for analysis. The FFT results of the vibration acceleration in the range of $0 \sim 30 \mathrm{~Hz}$ and $0 \sim 500 \mathrm{~Hz}$ are shown in Figure 12. 


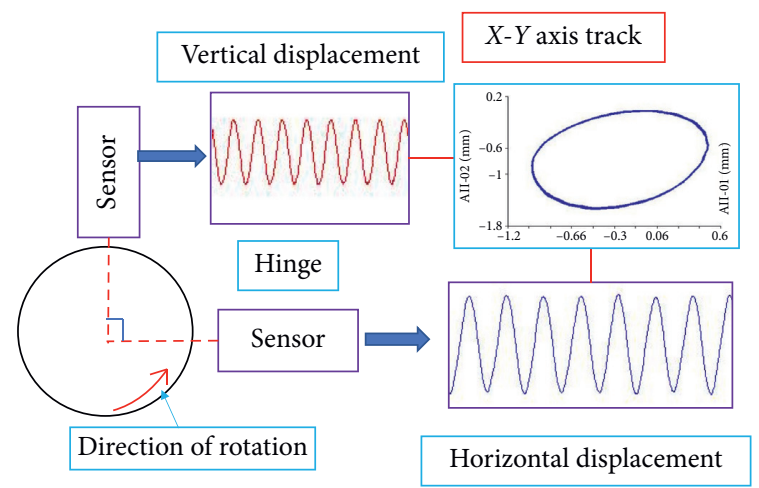

(a)

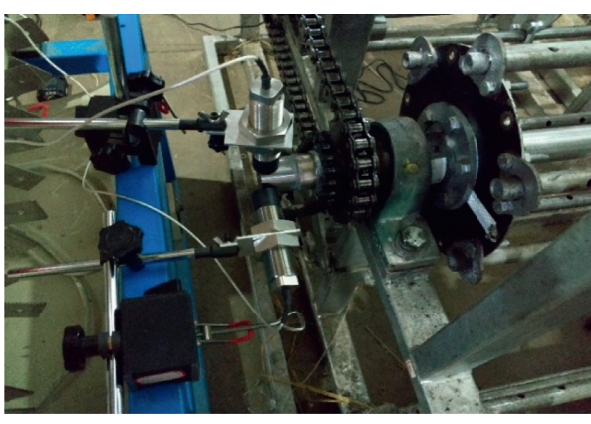

(b)

Figure 11: Principle diagram of eddy current sensor axis trajectory measurement and sensor installation. (a) Principle of eddy current test axis track. (b) Installation location of eddy current sensors.

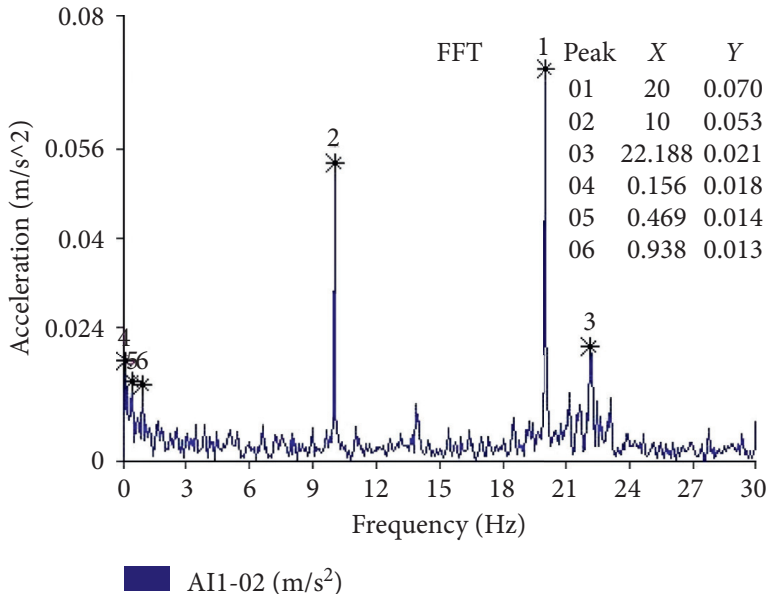

(a)

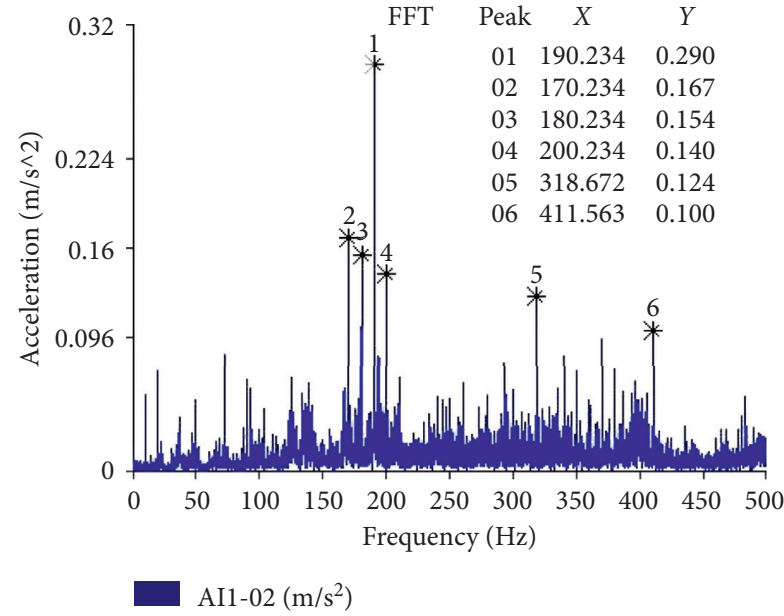

(b)

FIGURE 12: Single-cylinder frequency spectrum in the range of $0 \sim 30 \mathrm{~Hz}$ and $0 \sim 500 \mathrm{~Hz}$. (a) Spectrogram of single cylinder in the range of $0 \sim 30 \mathrm{~Hz}$. (b) Spectrogram of single cylinder in the range of $0 \sim 500 \mathrm{~Hz}$.

It can be seen from Figure 12 that the energy of the bearing seat in the range of $170 \sim 200 \mathrm{~Hz}$ was relatively large, and the vibration of this part may be mainly caused by the vibration of the transmission chain during the movement. During the transmission process, the number of teeth of the sprocket of cylinder I was 18, and the fundamental frequency was $10 \mathrm{~Hz}$, so the frequency spectrum at $180 \mathrm{~Hz}$ was largely caused by the meshing impact of the chain. In addition, the frequencies corresponding to the other main peaks were all multiples of the fundamental frequency of cylinder I. It can be seen that the position of the bearing seat was subject to greater impact from the chain vibration. In the range of $0 \sim 30 \mathrm{~Hz}$ for the single cylinder, the fundamental frequency of cylinder I and its double frequency were the main frequency components, and the peak value of the double frequency reflected the installation state of the cylinder shaft. As a result, the vibration of the transmission chain may be transmitted to the cylinder shaft, bearing seat and frame through the sprocket. Since the rotation frequency of the motor was the same as that of the cylinder I, it was not ruled out that the frequency component of this part of the bearing seat may be transmitted to this position by the chain vibration through the motor shaft and the frame. The impact energy generated by the chain drive was relatively large, but the actual effect required further analysis from the displacement response.

In order to analyze the impact of the transmission chain on the vibration state of the system, the test data of the single-cylinder rotating and the horizontal vibration data of the cylinder $\mathrm{I}$ in the $Y$ direction bearing seat position in the two-cylinder multilateral transmission are compared and analyzed. The frequency range during analysis was mainly divided into $0 \sim 30 \mathrm{~Hz}$ and $0 \sim 500 \mathrm{~Hz}$. The frequency spectrum diagram of the vibration response of the bearing seat position under various working conditions in single-cylinder drive is shown in Figure 13. The data under various working conditions are shown in Tables 3-5. 


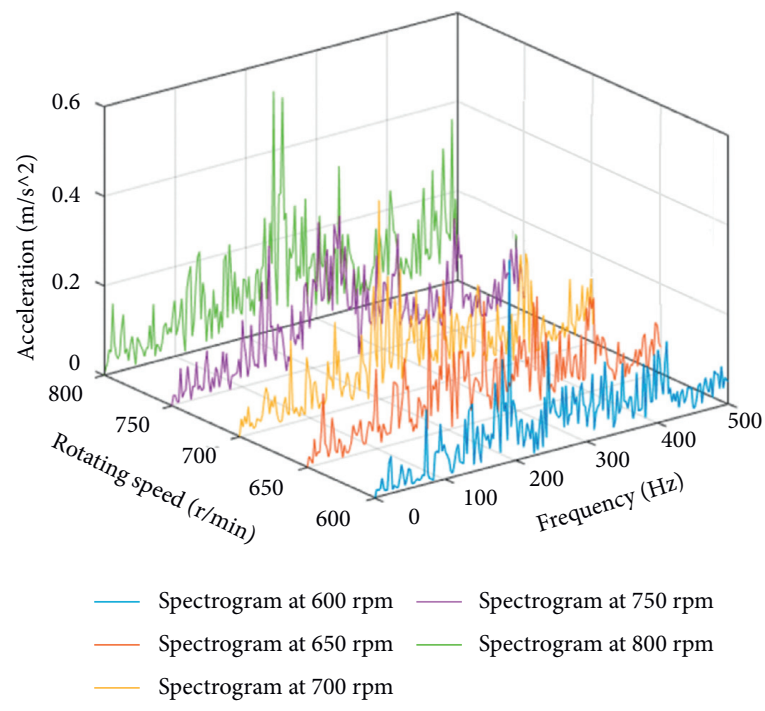

(a)

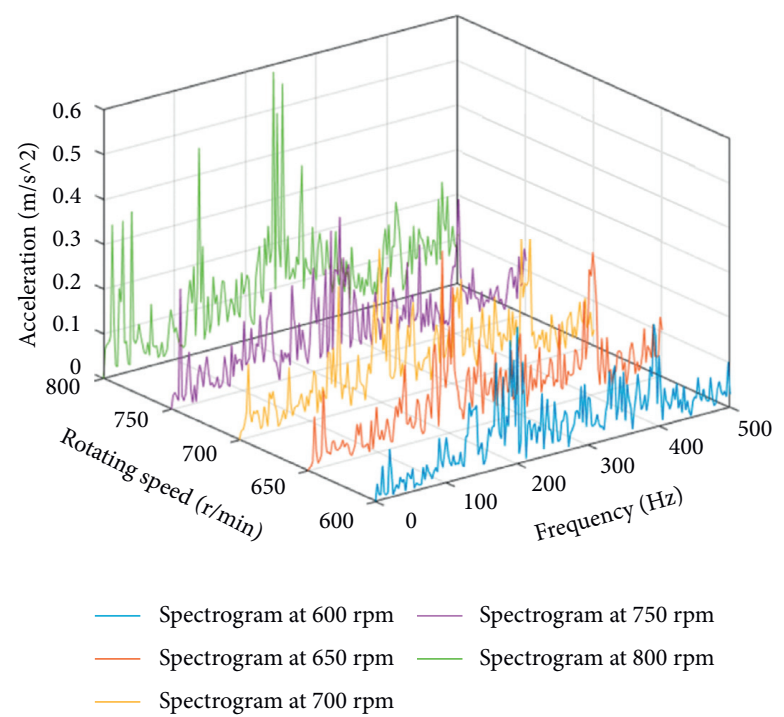

(b)

FIGURE 13: Frequency spectrum diagram under various working conditions in single-cylinder drive. (a) Single-cylinder drive without load. (b) Cylinder I with counterweight $127.89 \mathrm{~g}$.

TABle 3: FFT main data of vibration acceleration of cylinder I of bearing seat in $Y$ direction.

\begin{tabular}{|c|c|c|c|c|c|c|c|c|c|}
\hline \multirow{2}{*}{$\begin{array}{l}\text { Rotating speed } \\
\text { (r/min) }\end{array}$} & \multirow{2}{*}{$\begin{array}{l}\text { Frequency range } \\
(\mathrm{Hz})\end{array}$} & \multicolumn{4}{|c|}{ Single-cylinder drive without load } & \multicolumn{4}{|c|}{ Cylinder I with counterweight $127.89 \mathrm{~g}$} \\
\hline & & $\begin{array}{c}\text { Frequency } \\
(\mathrm{Hz})\end{array}$ & $\begin{array}{l}\text { Peak } \\
\left(\mathrm{m} / \mathrm{s}^{2}\right)\end{array}$ & $\begin{array}{c}\text { Frequency } \\
(\mathrm{Hz})\end{array}$ & $\begin{array}{l}\text { Peak } \\
\left(\mathrm{m} / \mathrm{s}^{2}\right)\end{array}$ & $\begin{array}{c}\text { Frequency } \\
(\mathrm{Hz})\end{array}$ & $\begin{array}{l}\text { Peak } \\
\left(\mathrm{m} / \mathrm{s}^{2}\right)\end{array}$ & $\begin{array}{c}\text { Frequency } \\
(\mathrm{Hz})\end{array}$ & $\begin{array}{l}\text { Peak } \\
\left(\mathrm{m} / \mathrm{s}^{2}\right)\end{array}$ \\
\hline \multirow{2}{*}{600} & $0 \sim 30$ & 20 & 0.073 & 10 & 0.046 & 10 & 0.088 & 20 & 0.074 \\
\hline & $0 \sim 500$ & 190.7 & 0.293 & 170.7 & 0.241 & 189.8 & 0.260 & 169.8 & 0.260 \\
\hline \multirow{2}{*}{650} & $0 \sim 30$ & 21.7 & 0.157 & 10.86 & 0.052 & 21.7 & 0.194 & 10.86 & 0.091 \\
\hline & $0 \sim 500$ & 401.3 & 0.269 & 206 & 0.173 & 400.6 & 0.275 & 195 & 0.238 \\
\hline \multirow{2}{*}{700} & $0 \sim 30$ & 11.64 & 0.058 & 22.4 & 0.050 & 11.64 & 0.133 & 23.3 & 0.064 \\
\hline & $0 \sim 500$ & 198.4 & 0.287 & 408.4 & 0.176 & 198.7 & 0.416 & 210.4 & 0.206 \\
\hline \multirow{2}{*}{750} & $0 \sim 30$ & 12.5 & 0.095 & 22.0 & 0.035 & 12.5 & 0.255 & 22.0 & 0.112 \\
\hline & $0 \sim 500$ & 237.6 & 0.358 & 219 & 0.250 & 237.4 & 0.366 & 12.5 & 0.255 \\
\hline \multirow{2}{*}{800} & $0 \sim 30$ & 26.72 & 0.122 & 13.36 & 0.149 & 26.64 & 0.382 & 13.36 & 0.341 \\
\hline & $0 \sim 500$ & 239.7 & 0.562 & 253.0 & 0.551 & 240.2 & 0.591 & 253.5 & 0.569 \\
\hline
\end{tabular}

TABLE 4: FFT main data of cylinder I of bearing seat in $Y$ direction under two-cylinder unilateral transmission.

\begin{tabular}{|c|c|c|c|c|c|c|c|c|c|}
\hline \multirow{2}{*}{$\begin{array}{l}\text { Rotating speed } \\
\text { (r/min) }\end{array}$} & \multirow{2}{*}{$\begin{array}{c}\text { Frequency range } \\
(\mathrm{Hz})\end{array}$} & \multicolumn{4}{|c|}{ Cylinder I with counterweight $127.89 \mathrm{~g}$} & \multicolumn{4}{|c|}{ Cylinder II with counterweight $227.89 \mathrm{~g}$} \\
\hline & & $\begin{array}{c}\text { Frequency } \\
(\mathrm{Hz})\end{array}$ & $\begin{array}{l}\text { Peak } \\
\left(\mathrm{m} / \mathrm{s}^{2}\right)\end{array}$ & $\begin{array}{c}\text { Frequency } \\
(\mathrm{Hz})\end{array}$ & $\begin{array}{l}\text { Peak } \\
\left(\mathrm{m} / \mathrm{s}^{2}\right)\end{array}$ & $\begin{array}{c}\text { Frequency } \\
(\mathrm{Hz})\end{array}$ & $\begin{array}{l}\text { Peak } \\
\left(\mathrm{m} / \mathrm{s}^{2}\right)\end{array}$ & $\begin{array}{c}\text { Frequency } \\
(\mathrm{Hz})\end{array}$ & $\begin{array}{l}\text { Peak } \\
\left(\mathrm{m} / \mathrm{s}^{2}\right)\end{array}$ \\
\hline \multirow{2}{*}{600} & $0 \sim 30$ & 22.2 & 0.172 & 10 & 0.081 & 22.3 & 0.217 & 20 & 0.063 \\
\hline & $0 \sim 500$ & 179.8 & 0.785 & 187.0 & 0.701 & 180 & 0.684 & 187.2 & 0.642 \\
\hline \multirow{2}{*}{650} & $0 \sim 30$ & 21.64 & 0.199 & 10.86 & 0.082 & 21.7 & 0.141 & 10.86 & 0.046 \\
\hline & $0 \sim 500$ & 194.8 & 0.684 & 210.4 & 0.548 & 195.2 & 0.770 & 203.0 & 0.755 \\
\hline \multirow{2}{*}{700} & $0 \sim 30$ & 11.64 & 0.140 & 21.95 & 0.055 & 11.64 & 0.043 & 8.438 & 0.036 \\
\hline & $0 \sim 500$ & 218.3 & 0.762 & 210 & 0.736 & 210.2 & 1.412 & 218.5 & 0.918 \\
\hline \multirow{2}{*}{750} & $0 \sim 30$ & 12.5 & 0.224 & 21.56 & 0.086 & 12.5 & 0.080 & 8.984 & 0.061 \\
\hline & $0 \sim 500$ & 225.3 & 0.657 & 234.3 & 0.501 & 224.6 & 0.772 & 233.5 & 0.755 \\
\hline \multirow{2}{*}{800} & $0 \sim 30$ & 13.28 & 0.333 & 26.56 & 0.327 & 13.28 & 0.095 & 9.61 & 0.065 \\
\hline & $0 \sim 500$ & 248.7 & 0.989 & 229.6 & 0.465 & 249.3 & 0.930 & 258.9 & 0.508 \\
\hline
\end{tabular}


TABLE 5: FFT main data of cylinder I of bearing seat in $Y$ direction under two-cylinder bilateral transmission.

\begin{tabular}{|c|c|c|c|c|c|c|c|c|c|}
\hline \multirow{2}{*}{$\begin{array}{l}\text { Rotating speed } \\
(\mathrm{r} / \mathrm{min})\end{array}$} & \multirow{2}{*}{$\begin{array}{c}\text { Frequency range } \\
(\mathrm{Hz})\end{array}$} & \multicolumn{4}{|c|}{ Cylinder I with counterweight $127.89 \mathrm{~g}$} & \multicolumn{4}{|c|}{ Cylinder II with counterweight $227.89 \mathrm{~g}$} \\
\hline & & $\begin{array}{c}\text { Frequency } \\
(\mathrm{Hz})\end{array}$ & $\begin{array}{l}\text { Peak } \\
\left(\mathrm{m} / \mathrm{s}^{2}\right)\end{array}$ & $\begin{array}{c}\text { Frequency } \\
(\mathrm{Hz})\end{array}$ & $\begin{array}{l}\text { Peak } \\
\left(\mathrm{m} / \mathrm{s}^{2}\right)\end{array}$ & $\begin{array}{c}\text { Frequency } \\
(\mathrm{Hz})\end{array}$ & $\begin{array}{l}\text { Peak } \\
\left(\mathrm{m} / \mathrm{s}^{2}\right)\end{array}$ & $\begin{array}{c}\text { Frequency } \\
(\mathrm{Hz})\end{array}$ & $\begin{array}{r}\text { Peak } \\
\left(\mathrm{m} / \mathrm{s}^{2}\right)\end{array}$ \\
\hline \multirow{2}{*}{600} & $0 \sim 30$ & 22.3 & 0.105 & 10 & 0.085 & 20 & 0.058 & 10 & 0.039 \\
\hline & $0 \sim 500$ & 187.2 & 0.317 & 172.9 & 0.287 & 187.4 & 0.448 & 173 & 0.423 \\
\hline \multirow{2}{*}{650} & $0 \sim 30$ & 21.64 & 0.208 & 10.86 & 0.101 & 21.64 & 0.163 & 10.86 & 0.040 \\
\hline & $0 \sim 500$ & 195 & 0.440 & 187.2 & 0.425 & 187.2 & 0.356 & 97.5 & 0.373 \\
\hline \multirow{2}{*}{700} & $0 \sim 30$ & 11.64 & 0.149 & 23.36 & 0.053 & 11.64 & 0.048 & 21.56 & 0.043 \\
\hline & $0 \sim 500$ & 210 & 0.289 & 198 & 0.219 & 210.1 & 0.279 & 105 & 0.209 \\
\hline \multirow{2}{*}{750} & $0 \sim 30$ & 12.5 & 0.239 & 25 & 0.126 & 12.5 & 0.085 & 8.984 & 0.046 \\
\hline & $0 \sim 500$ & 225.2 & 0.489 & 237.6 & 0.307 & 225.2 & 0.434 & 216.3 & 0.265 \\
\hline \multirow{2}{*}{800} & $0 \sim 30$ & 13.36 & 0.318 & 26.8 & 0.242 & 13.36 & 0.124 & 9.609 & 0.060 \\
\hline & $0 \sim 500$ & 240.2 & 1.023 & 120.1 & 0.404 & 240.8 & 0.674 & 227.3 & 0.312 \\
\hline
\end{tabular}

From the data in Figure 13 and Tables 3-5, it can be seen that with the increase of the rotation speed under different working conditions, the magnitude of the unbalanced vibration of the cylinder I at the fundamental frequency gradually increased. When the unbalanced mass was not applied to the cylinder I, its vibration at the fundamental frequency was small. The amplitude at this point cannot be considered to be completely caused by the unbalance of cylinder I. Since the cylinder I had already done the relevant dynamic balance, the amplitude at the fundamental frequency may be largely caused by the rotation of the motor. In addition, the vibration at the double frequency of the cylinder I during the working process was more obvious when the speed was low and the imbalance was small, so there may be misalignment of the axis during installation. When the unbalance on the cylinder I was small, its vibration energy at high frequencies was significantly higher than that at low frequencies. With the increase of the rotational speed and the increase of the unbalanced mass on the cylinder I, its vibration energy at the fundamental frequency became the main frequency component in the entire frequency range. The frequency components at high frequencies were mostly at the multiples of the fundamental frequency of the cylinder, so the energy of this part came from the vibration of the transmission chain to a large extent.

Through the comparison and analysis of the main data under different working conditions, it can be known that the existence of the transmission chain changed the vibration amplitude of the cylinder I at the fundamental frequency, and this influence relationship was very complicated. Take the data of two-cylinder unilateral transmission and singlecylinder transmission as examples for analysis. When the motor speed was $600 \mathrm{r} / \mathrm{min}$ and the cylinder I rotated alone, its amplitude at the fundamental frequency was $0.088 \mathrm{~m} / \mathrm{s}^{2}$. When it was connected to the cylinder II, the amplitude at the fundamental frequency was $0.081 \mathrm{~m} / \mathrm{s}^{2}$. The peak value of cylinder I at the fundamental frequency was reduced by $8 \%$. When the motor speed was $700 \mathrm{r} / \mathrm{min}$ and the cylinder I rotated alone, its amplitude at the fundamental frequency was $0.133 \mathrm{~m} / \mathrm{s}^{2}$. When it was connected to the cylinder II, the amplitude at the fundamental frequency was $0.140 \mathrm{~m} / \mathrm{s}^{2}$. The peak value of cylinder I at the fundamental frequency was increased by $5 \%$. When the motor speed was in the range of $600 \sim 800 \mathrm{r} / \mathrm{min}$, the existence of the transmission chain had different effects on the vibration of the cylinder I at the fundamental frequency, and the results under each working condition had a difference of $5 \%$ to $10 \%$. In addition, the position of the transmission chain also had a certain influence on the amount of vibration at the fundamental frequency. Take the test results of two-cylinder unilateral transmission and two-cylinder bilateral transmission as an example for analysis. When the motor speed was $600 \mathrm{r} / \mathrm{min}$, the amplitude of cylinder I at the fundamental frequency during bilateral transmission was $0.081 \mathrm{~m} / \mathrm{s}^{2}$. The vibration amplitude at the fundamental frequency was $0.085 \mathrm{~m} / \mathrm{s}^{2}$ during bilateral transmission, which increased to a certain extent. In the test, the transmission chain was closer to the tested bearing seat during unilateral transmission. By comparing the test data at other speeds, it can be obtained that the vibration amplitude at the fundamental frequency of the section close to the chain would be reduced, and the degree of reduction at different speeds would be different. When the motor speed was in the range of $600 \sim 800 \mathrm{r} / \mathrm{min}$, the peak value of the acceleration changes of the cylinder I at the fundamental frequency was 5\% 15\%. From the above data, it can be seen that the transmission chain and transmission mode would have an impact on the vibration amplitude of the cylinder in the system at the fundamental frequency, and the overall impact was $5 \%$ to $15 \%$. The influence relationship between the transmission chain and the movement state of the cylinder was more complicated. It may be that the existence of the transmission chain changed the stiffness and damping of the system, which ultimately led to a change in the response of unbalance. With the increase of the transmission chain and the complexity of the transmission relationship, the degree of this influence may be further increased. Therefore, it was necessary to further test and analyze the vibration response under multiple cylinders.

3.1.2. Analysis of Vibration Characteristics of Bearing Seat during Multicylinder Transmission. In order to further analyze the influence of the transmission chain on the vibration 
state of the entire system, especially the vibration response at the fundamental frequency of the cylinder, the vibration characteristics of multiple cylinders in parallel transmission were analyzed. In a multicylinder system, as the number of transmission chains and cylinders increased, the degree of influence of the transmission method may be more significant. In order to fully reflect the impact of the transmission system on the entire cylinder system, the vibration state of the first two cylinders in the multicylinder system was analyzed. The results were compared with the two-cylinder transmission to further analyze the influence of the drive chain on the vibration state of the system. In order to facilitate comparison and analysis, the horizontal vibration of the cylinder I in the $Y$-direction bearing seat position was analyzed. The frequency range during analysis was mainly divided into acceleration peaks in the range of $0 \sim 30 \mathrm{~Hz}$ and $0 \sim 500 \mathrm{~Hz}$. The main data are shown in Tables 6 and 7.

It can be seen from Tables 6 and 7 that when the number of transmission chains in the system increased, the vibration of the cylinder I at the fundamental frequency also changed. Due to the increase of the transmission chain and the number of cylinders, the rigidity and damping of the entire multicylinder system changed resulting in a change in the vibration state of cylinder I. Take the test data of two-cylinder unilateral transmission and three-cylinder unilateral transmission as examples for analysis. When the motor speed was $600 \mathrm{r} / \mathrm{min}$ and there was an unbalanced mass on the cylinder I, its vibration peaks at the fundamental frequency were $0.081 \mathrm{~m} / \mathrm{s}^{2}$ and $0.072 \mathrm{~m} / \mathrm{s}^{2}$, which were decreased by $11.1 \%$. When the motor speed was $650 \mathrm{r} / \mathrm{min}$, its vibration peaks at the fundamental frequency were $0.082 \mathrm{~m} /$ $\mathrm{s}^{2}$ and $0.103 \mathrm{~m} / \mathrm{s}^{2}$, an increase of $27 \%$. However, in some cases, the vibration response at the fundamental frequency was very close. For example, when the rotation speed was $750 \mathrm{r} / \mathrm{min}$ and there was an unbalanced mass on the cylinder $\mathrm{I}$, the vibration peaks at the fundamental frequency were, respectively, $0.224 \mathrm{~m} / \mathrm{s}^{2}$ and $0.221 \mathrm{~m} / \mathrm{s}^{2}$, a decrease of $1.3 \%$. The vibration acceleration signals of the bearing seat positions of cylinder II and cylinder III under the same working conditions were processed and analyzed. The Fourier transform results of each bearing seat position showed that the existence of the transmission chain and the transmission mode in the state of multiple cylinders would affect the vibration response of the cylinder at the fundamental frequency. Take the test data of cylinder II in double-cylinder unilateral transmission and three-cylinder unilateral transmission as an example for analysis. When the rotation speed was $600 \mathrm{r} / \mathrm{min}$ and there was an unbalanced mass on the cylinder II, the vibration peaks at the fundamental frequency were $0.018 \mathrm{~m} / \mathrm{s}^{2}$ and $0.024 \mathrm{~m} / \mathrm{s}^{2}$, which was an increase of $33.3 \%$. In addition, from the main data at other speeds, it can be seen that the existence of the transmission chain had a complicated influence on the vibration response of the system, which was not only related to the unbalance of the cylinder itself but also had a great relationship with the speed. Choy proposed a mathematical model that couples the gear-bearing-rotor system with the gearbox and solved the model by using the modal synthesis method [32]. For the gear system, the influence of the transmission position on the coupling effect of the system was not considered. However, when it comes to the chain transmission system, the position of the transmission system will change the boundary conditions of the working unit in the system. From the data in Tables 6 and 7, it can be seen that not only the transmission chain itself would affect the vibration state of the system, but the change in the transmission mode also affected the vibration state of the system.

The analysis of the vibration frequency components at the bearing seat showed that the main frequency components of the vibration in the range of $0 \sim 500 \mathrm{~Hz}$ were the multiples of the cylinder system, and there was a multiple relationship with the number of teeth of the sprocket. Take the data at $600 \mathrm{r} / \mathrm{min}$ and $750 \mathrm{r} / \mathrm{min}$ as an example for analysis. The number of sprocket teeth installed on cylinder I was 18. Due to the meshing impact of the transmission chain, it was easy to produce excitation components with frequencies of $180 \mathrm{~Hz}$ and $225 \mathrm{~Hz}$. The actual test result was that when the rotation speed of the cylinder I was $600 \mathrm{r} / \mathrm{min}$, the main frequency component of the vibration at the position of the bearing seat was about $180 \mathrm{~Hz}$. When the rotation speed of the cylinder I was $750 \mathrm{r} / \mathrm{min}$, the main frequency component of the vibration when it was in the bearing seat was about $225 \mathrm{~Hz}$. Due to the frequency resolution, there was a certain difference in size. The frequency corresponding to the peak vibration acceleration was $225.4 \mathrm{~Hz}$ in unilateral transmission and $224.7 \mathrm{~Hz}$ in bilateral transmission.

In addition, the frequency component of the adjacent cylinder appeared in the vibration frequency of the bearing seat of the cylinder I. Taking the data of two-cylinder transmission and rotating speed of $800 \mathrm{r} / \mathrm{min}$ as an example, an excitation component with a frequency of $9.853 \mathrm{H}$ appeared in the low-frequency part, and this frequency was exactly the fundamental frequency of cylinder II. This phenomenon was more obvious in the bearing seat of the cylinder II. Since the rotation frequency of the motor was consistent with the fundamental frequency of the cylinder I, the vibration response generated by the two was superimposed in the bearing seat of the cylinder II, even exceeding the vibration of the cylinder II itself at the fundamental frequency. It can be obtained that the vibration source of the bearing seat position mainly included three, namely, the meshing impact of the transmission chain, the unbalance of the cylinder, and the rotation of the motor. Among them, the meshing impact of the transmission chain had the largest impact energy, followed by the rotation of the motor and the unbalance of the cylinder. From the above results, it can be seen that the vibrations of adjacent cylinders can be transmitted to each other, but the actual transfer path was not clear. It may be transmitted through the frame or through the transmission chain, and it was not clear which was the main transfer path of vibration.

3.2. Analysis of the Transmission Characteristics of the Frame of the Multicylinder Transmission. In order to further analyze the main transfer path of vibration, the results of the vibration transmission test of the frame were analyzed. There 
TABLE 6: FFT main data of cylinder I of bearing seat in $Y$ direction under three-cylinder unilateral transmission.

\begin{tabular}{|c|c|c|c|c|c|c|c|c|c|}
\hline \multirow{2}{*}{$\begin{array}{l}\text { Rotating speed } \\
\text { (r/min) }\end{array}$} & \multirow{2}{*}{$\begin{array}{c}\text { Frequency range } \\
(\mathrm{Hz})\end{array}$} & \multicolumn{4}{|c|}{ Cylinder I with counterweight $127.89 \mathrm{~g}$} & \multicolumn{4}{|c|}{ Cylinder II with counterweight $227.89 \mathrm{~g}$} \\
\hline & & $\begin{array}{l}\text { Frequency } \\
(\mathrm{Hz})\end{array}$ & $\begin{array}{c}\text { Peak } \\
\left(\mathrm{m} / \mathrm{s}^{2}\right)\end{array}$ & $\begin{array}{l}\text { Frequency } \\
(\mathrm{Hz})\end{array}$ & $\begin{array}{c}\text { Peak } \\
\left(\mathrm{m} / \mathrm{s}^{2}\right)\end{array}$ & $\begin{array}{c}\text { Frequency } \\
(\mathrm{Hz})\end{array}$ & $\begin{array}{c}\text { Peak } \\
\left(\mathrm{m} / \mathrm{s}^{2}\right)\end{array}$ & $\begin{array}{c}\text { Frequency } \\
(\mathrm{Hz})\end{array}$ & $\begin{array}{l}\text { Peak } \\
\left(\mathrm{m} / \mathrm{s}^{2}\right)\end{array}$ \\
\hline \multirow{2}{*}{600} & $0 \sim 30$ & 22.3 & 0.150 & 10 & 0.072 & 22.3 & 0.107 & 10 & 0.031 \\
\hline & $0 \sim 500$ & 180.4 & 0.661 & 187.5 & 0.466 & 180.4 & 0.654 & 194.8 & 0.582 \\
\hline \multirow{2}{*}{650} & $0 \sim 30$ & 21.72 & 0.221 & 10.86 & 0.103 & 21.7 & 0.155 & 10.86 & 0.047 \\
\hline & $0 \sim 500$ & 195.5 & 0.683 & 211.2 & 0.624 & 195.2 & 0.649 & 203 & 0.591 \\
\hline \multirow{2}{*}{700} & $0 \sim 30$ & 11.72 & 0.137 & 23.44 & 0.094 & 25.16 & 0.093 & 11.64 & 0.061 \\
\hline & $0 \sim 500$ & 210.5 & 0.891 & 218.9 & 0.677 & 209.8 & 0.918 & 218.1 & 0.718 \\
\hline \multirow{2}{*}{750} & $0 \sim 30$ & 12.5 & 0.221 & 21.56 & 0.102 & 12.5 & 0.083 & 27.03 & 0.047 \\
\hline & $0 \sim 500$ & 225.1 & 0.658 & 234.1 & 0.611 & 234.4 & 0.886 & 216.3 & 0.87 \\
\hline \multirow{2}{*}{800} & $0 \sim 30$ & 13.35 & 0.206 & 26.64 & 0.118 & 13.4 & 0.094 & 26.8 & 0.057 \\
\hline & $0 \sim 500$ & 249.4 & 0.811 & 230.2 & 0.543 & 250.7 & 0.857 & 231.5 & 0.608 \\
\hline
\end{tabular}

TABLE 7: FFT main data of cylinder I of bearing seat in $Y$ direction under three-cylinder bilateral transmission.

\begin{tabular}{|c|c|c|c|c|c|c|c|c|c|}
\hline \multirow{2}{*}{$\begin{array}{l}\text { Rotating speed } \\
(\mathrm{r} / \mathrm{min})\end{array}$} & \multirow{2}{*}{$\begin{array}{l}\text { Frequency range } \\
\qquad(\mathrm{Hz})\end{array}$} & \multicolumn{4}{|c|}{ Cylinder I with counterweight $127.89 \mathrm{~g}$} & \multicolumn{4}{|c|}{ Cylinder II with counterweight $227.89 \mathrm{~g}$} \\
\hline & & $\begin{array}{c}\text { Frequency } \\
(\mathrm{Hz})\end{array}$ & $\begin{array}{l}\text { Peak } \\
\left(\mathrm{m} / \mathrm{s}^{2}\right)\end{array}$ & $\begin{array}{c}\text { Frequency } \\
(\mathrm{Hz})\end{array}$ & $\begin{array}{l}\text { Peak } \\
\left(\mathrm{m} / \mathrm{s}^{2}\right)\end{array}$ & $\begin{array}{c}\text { Frequency } \\
(\mathrm{Hz})\end{array}$ & $\begin{array}{l}\text { Peak } \\
\left(\mathrm{m} / \mathrm{s}^{2}\right)\end{array}$ & $\begin{array}{c}\text { Frequency } \\
(\mathrm{Hz})\end{array}$ & $\begin{array}{l}\text { Peak } \\
\left(\mathrm{m} / \mathrm{s}^{2}\right)\end{array}$ \\
\hline \multirow{2}{*}{600} & $0 \sim 30$ & 22.3 & 0.15 & 10 & 0.083 & 20 & 0.047 & 10 & 0.036 \\
\hline & $0 \sim 500$ & 180.4 & 0.434 & 173.2 & 0.311 & 180.4 & 0.482 & 187.1 & 0.419 \\
\hline \multirow{2}{*}{650} & $0 \sim 30$ & 21.7 & 0.19 & 10.86 & 0.086 & 21.68 & 0.163 & 10.86 & 0.037 \\
\hline & $0 \sim 500$ & 97.5 & 0.43 & 195 & 0.302 & 202.7 & 0.327 & 97.5 & 0.277 \\
\hline \multirow{2}{*}{700} & $0 \sim 30$ & 11.66 & 0.136 & 25.21 & 0.093 & 25.2 & 0.149 & 11.66 & 0.053 \\
\hline & $0 \sim 500$ & 210.3 & 0.382 & 201.8 & 0.223 & 210.1 & 0.309 & 201.7 & 0.232 \\
\hline \multirow{2}{*}{750} & $0 \sim 30$ & 12.5 & 0.249 & 25 & 0.167 & 25 & 0.072 & 12.5 & 0.056 \\
\hline & $0 \sim 500$ & 225.2 & 0.347 & 112.6 & 0.305 & 224.7 & 0.367 & 161.8 & 0.266 \\
\hline \multirow{2}{*}{800} & $0 \sim 30$ & 13.31 & 0.334 & 22.9 & 0.254 & 13.31 & 0.093 & 9.583 & 0.052 \\
\hline & $0 \sim 500$ & 240.0 & 0.671 & 13.31 & 0.334 & 240 & 0.872 & 249.6 & 0.375 \\
\hline
\end{tabular}

were three measuring points in the frame transmission characteristic test, and the vibration state of each measuring point reflected the role played in the frame during the movement of the multicylinder system. The type of sensors used in the experiment was acceleration sensors. The frequency component of the frame vibration can be obtained by FFT transformation of the acceleration signal, and then the vibration source of the frame can be found through the analysis of the frequency component. The peak value at each frequency reflected the energy of the frequency component, so the impact energy change of the frame during the transmission process can be obtained through the signal processing and analysis of these three measuring points.

The vibration acceleration signals of the three measuring points were processed, and the vibration response at each speed was obtained. The Fourier transform of the vibration acceleration signal can obtain the frequency component of the frame vibration. Each acceleration sensor measured vibration in three directions of the system. Due to the large unbalanced mass on the cylinders in the test, the forced vibration caused by this would drive the entire system to vibrate in the horizontal and vertical directions. Therefore, the influence of axial movement on the vibration of the system was not considered during the test. Since there were three main excitation sources in the entire system, the frequency components caused by the imbalance of the engine and the cylinder were mainly concentrated in the lowfrequency region. Therefore, the horizontal vibration results of the cylinder I with a rotation speed of $780 / \mathrm{min}$ and a frequency range of $0 \sim 20 \mathrm{~Hz}$ were analyzed. The vibration acceleration signals of the three measuring points were transformed by FFT, and the result is shown in Figure 14.

When the rotation speed of the motor was $600 \sim 800 \mathrm{r}$ / $\min$, the main vibration data of the transmission frame in the horizontal direction within $0 \sim 20 \mathrm{~Hz}$ are shown in Table 8 .

When the rotation speed of the motor was $600 \sim 800 \mathrm{r} /$ min, the horizontal vibration transmission trend of the frame within $0 \sim 20 \mathrm{~Hz}$ is shown in Figure 15.

From the data in Figure 15 and Table 8, it can be seen that in the frequency components of the vibration signals at the bearing seat positions of the cylinder I and cylinder II, the vibration peaks corresponding to the fundamental frequency of the cylinder I all exceed the vibration excited by the cylinder II. It meant that the impact energy generated by the vibration source with cylinder I as the base frequency on the frame exceeded the energy produced by the cylinder II as the base frequency. In the multicylinder test bench, the motor was installed on the frame as the power source, so the vibration generated by the motor during the rotation would be transmitted to various positions of the frame. In addition, there was unbalanced mass on the cylinder I, and the vibration caused by the unbalance of the cylinder I also contributed to the vibration of the frame. Since the motor and cylinder I were connected by a transmission chain and the transmission ratio between them was 1 , the vibration energy generated by the two would be superimposed on the 


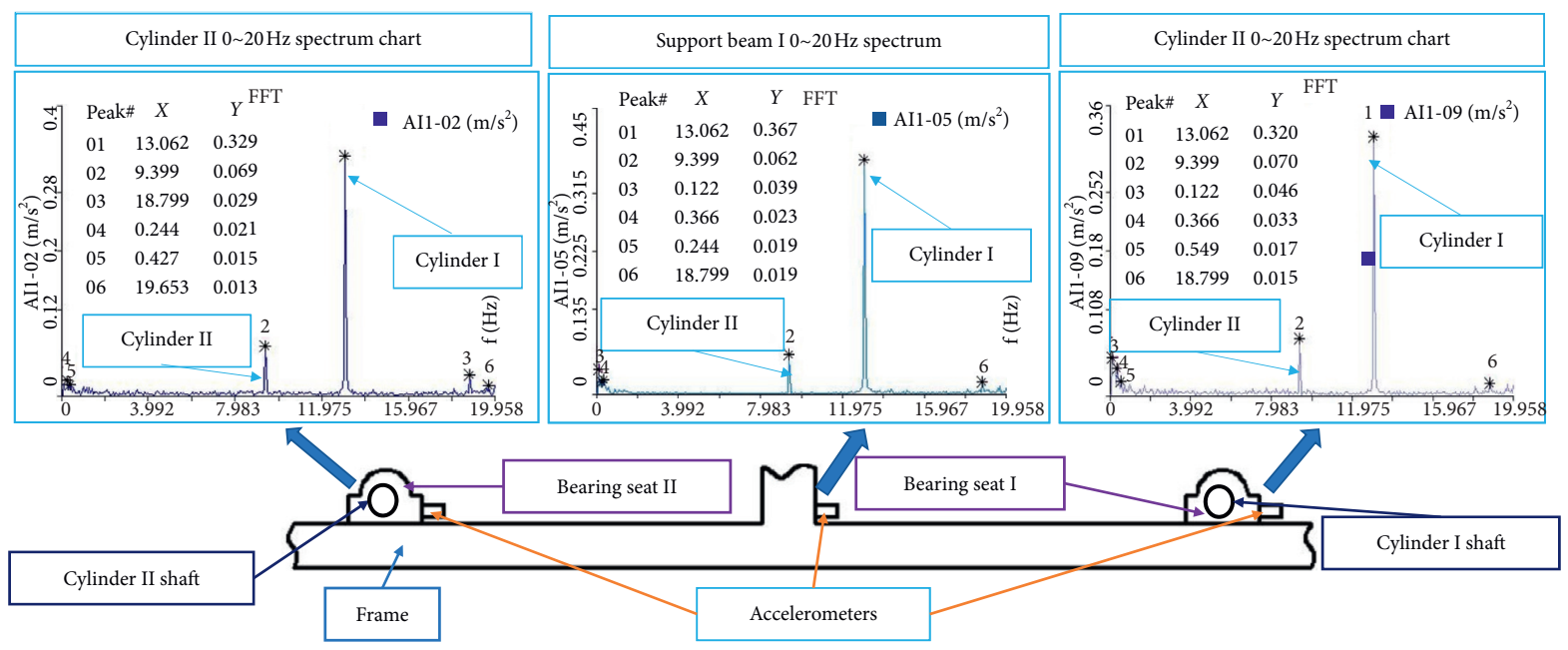

FIGURE 14: The frequency spectrum of the vibration signal of each measuring point at $780 \mathrm{r} / \mathrm{min}$.

frame. As a result, the vibration response of the frame in the low-frequency range showed that the vibration at the fundamental frequency of the cylinder I was larger. In the test of frame transmission characteristics, the unbalanced mass on cylinder II was larger than that on cylinder I, and the size and structure of cylinder I and cylinder II were exactly the same. Therefore, the vibration energy generated by the unbalance of the cylinder I should be slightly smaller than that of the cylinder II. It can be seen that the main vibration energy of the frame in the low-frequency range came from the vibration generated by the motor and the unbalance of cylinders. Among them, the motor was a main source of excitation of the frame, and the vibration caused by the unbalance of the cylinders was also an important factor of the frame vibration.

It can be seen from the vibration spectrogram of each position that the transmission efficiency of the frame for the vibration energy at each frequency was higher than $80 \%$. Xu et al. tested the vibration state of the combine harvester cab position under various working conditions. The vibration data under various working conditions showed that almost all the vibration transmission efficiency coefficients at low frequencies were greater than 1 . It showed that the vibration transmission efficiency of the whole machine was very high, and the frame was an important medium for the vibration transmission of the whole machine [33]. In addition, because of the differences in the structure of the frame at different positions, there were certain differences in the sensitivity to the vibration energy generated by the excitation source. It can be seen from the spectrogram at the support beam of the frame in Figure 14 that the peak of the vibration generated by the motor and the cylinder I exceeded the vibration response at the cylinder bearing seat. It can be seen from the law of the transmission process of the vibration generated by the unbalanced response of the cylinder II that the overall energy exhibited a decay trend during the transmission process. Since the vibration transfer path between cylinder I and cylinder II was exactly the same, it can be seen that the unbalance of cylinder I should also show a tendency of attenuation during the transmission process. However, the peak value of the frame support beam at the fundamental frequency showed an increasing trend at some speeds. It can be seen that the main reason for this phenomenon was that the vibration generated by the motor had a larger energy at this position. It was also possible that the rigidity of this position was relatively small relative to the position of the bearing seat, which made it more sensitive to the vibration generated by the excitation source, resulting in this position showing an increasing trend under the superposition of the vibration energy generated by the motor and the cylinder I.

The Fourier transform result of the acceleration signal showed that the actual vibration of the frame was the result of the vibration excitation of multiple frequency components. The peak value reflected the impact energy of the system at different frequencies. However, the magnitude of the acceleration did not reflect the actual magnitude of the displacement. Since the FFT transformation of acceleration had a tendency to amplify high-frequency components, the actual effect of frame vibration should be analyzed from the actual displacement. After the actual displacement of each position of the frame was transformed by FFT, the vibration displacement at each frequency can be obtained, and the displacement spectrum in the horizontal direction was taken as an example for analysis. Since the analysis result had a wide frequency range but the main peaks were concentrated in the low-frequency range, the abscissa of the processing result was changed to a logarithmic display format, so that the results of the low-frequency part were displayed more clearly. When the motor speed was $780 \mathrm{r} / \mathrm{min}$, the horizontal displacement time-domain diagram and frequency-domain diagram of the frame in the horizontal direction are shown in Figure 16. The main data of the frame displacement and spectrogram under other working conditions are shown in Table 9.

Take the data when the motor speed was $780 \mathrm{r} / \mathrm{min}$ as an example for analysis. According to the time-domain vibration signal of the frame in the horizontal direction, the maximum value was $0.142 \mathrm{~mm}$ and the minimum value was $-0.063 \mathrm{~mm}$. The displacement of the frame in the entire horizontal direction was $0.205 \mathrm{~mm}$. Since the eddy current 


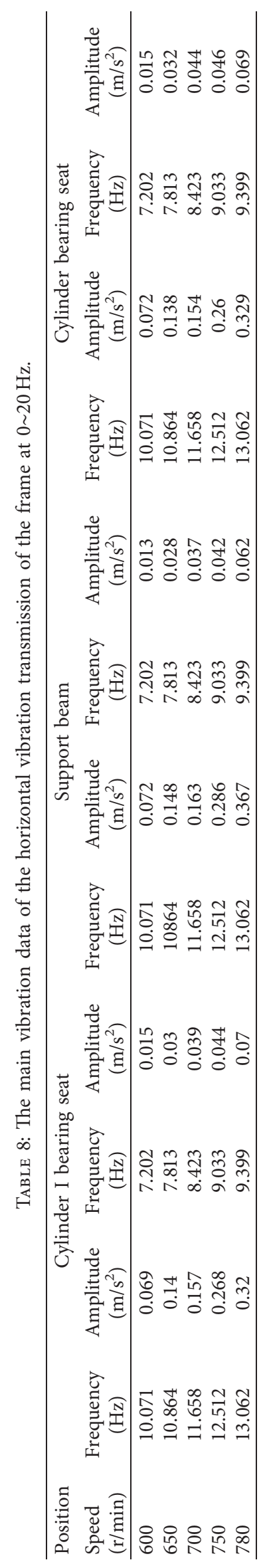




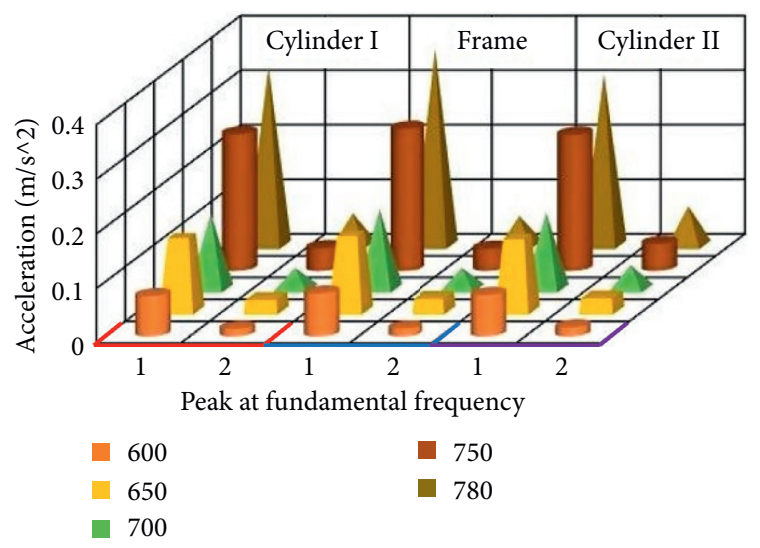

FIgURE 15: Frame transmission characteristic diagram.

sensor had been zeroed before the test, it can be seen that the displacement of the frame in the horizontal direction mainly moved along the positive direction of the sensor. An important reason for this phenomenon was that the rotation of each cylinder on the frame was counterclockwise, which made the entire system have the inertia of moving in one direction. If the rigidity of the frame was insufficient or could not be completely fixed, the entire frame and the multicylinder system would move in one direction. Therefore, the rigidity of the frame and the installation stability of the supporting parts of the entire system are an important factor for the stability of the entire system.

It can be seen from the displacement FFT results that the frequency components of the frame displacement were mainly concentrated in the low-frequency part, and the frame displacement caused by the high-frequency part was small, basically about 1 micron. When the motor speed was $780 \mathrm{r} / \mathrm{min}$, the fundamental frequency of cylinder I was $13 \mathrm{~Hz}$, and the fundamental frequency of adjacent cylinder was $9.399 \mathrm{~Hz}$. From the spectrogram of the rack displacement, it can be seen that the peak values at these two frequencies were relatively large. At other frequencies, they were generally the multiples of the two excitation frequencies and the simple harmonic frequencies generated by the transmission chain. Since the rotation frequency of the cylinder I and the motor were the same, the excitation of the two on frame may be superimposed. Therefore, in order to peel off the influence of the cylinder I and the motor on the frame displacement, it was necessary to compare the contribution of the vibration response of the cylinder I and the cylinder II to the frame vibration displacement. Since the structure of the cylinder I and cylinder II were exactly same and the measured frame position was located in the middle position between the two cylinders, there were many similarities in the excitation conditions of the two cylinders. Because the imbalance on cylinder II was larger than that on cylinder I, the contribution of cylinder II to the vibration response of the frame was larger than that of cylinder I. It can be seen from the spectrogram of the frame displacement that the frame displacement response caused by the unbalance of the cylinder II was $0.024 \mathrm{~mm}$. Therefore, the contribution of the vibration caused by the unbalance of the cylinder I to the displacement response of the frame was less than $0.024 \mathrm{~mm}$. The displacement response of the frame at a frequency of $13 \mathrm{~Hz}$ was $0.112 \mathrm{~mm}$, which was much larger than $0.024 \mathrm{~mm}$. It can be seen that the motor was the main source of vibration of the frame, and the energy generated by the rotation of the cylinder on the frame caused the frame to produce certain vibration. The vibration generated by other high-frequency excitation sources such as the transmission chain had a relatively small impact on the actual vibration of the frame.

It can be seen from the data in Table 9 that the vertical displacement of the frame was the smallest, which may be due to the greater rigidity of the frame in the vertical direction. The frame was fixed on the ground, so its vertical vibration was damped by the bottom surface; as a result, its vibration was smaller compared to the other two directions. The frame had the largest vibration in the horizontal direction, followed by the axial direction of the rotating shaft. The comparison of the vibration response of the frame at each main frequency in the axial direction showed that the frame was less vibrated by the unbalanced excitation of the cylinder in the axial direction. The rotation frequency of the motor was the same as the fundamental frequency of cylinder I, so its vibration response at this frequency was relatively large, while the vibration at the fundamental frequency of cylinder II was relatively small and can basically be ignored. It can be seen that the axial vibration of the frame was largely affected by the motor. In addition to the vibration response stimulated by the motor rotation, a considerable part of the energy came from the excitation at other frequencies, which may come from the high-frequency vibration generated by the transmission chain. Pang et al. used the data processing method of short-time Fourier transform to analyze the vibration of each vibration source of the combine harvester. The results showed that the vibration of the engine was the largest, which was an important source of excitation for the whole machine [34]. It can be seen that the vibration of the frame in the horizontal and vertical directions mainly came from the excitation generated by the motor and the cylinders, and the vertical vibration was relatively small. The vibration of the frame in the axial direction mainly came from the rotation of the motor and the transmission of the chain.

\subsection{Test Results and Analysis of Shaft End Vibration Char-} acteristics under Multicylinder Transmission. It was known from the frame transmission test that the frame was a main path of vibration transmission of the multicylinder system. The vibration component on the frame was complex, and the rotating shaft in the multicylinder system was installed on the frame through a bearing seat. Whether these excitation components would affect the state of the rotating shaft during the transmission process was very important for the analysis of the vibration transmission characteristics of the entire system. Therefore, in order to further analyze the state and excitation components of the rotating shaft, further analysis and processing of its axis trajectory was required. The different axis trajectories reflect the movement of the 


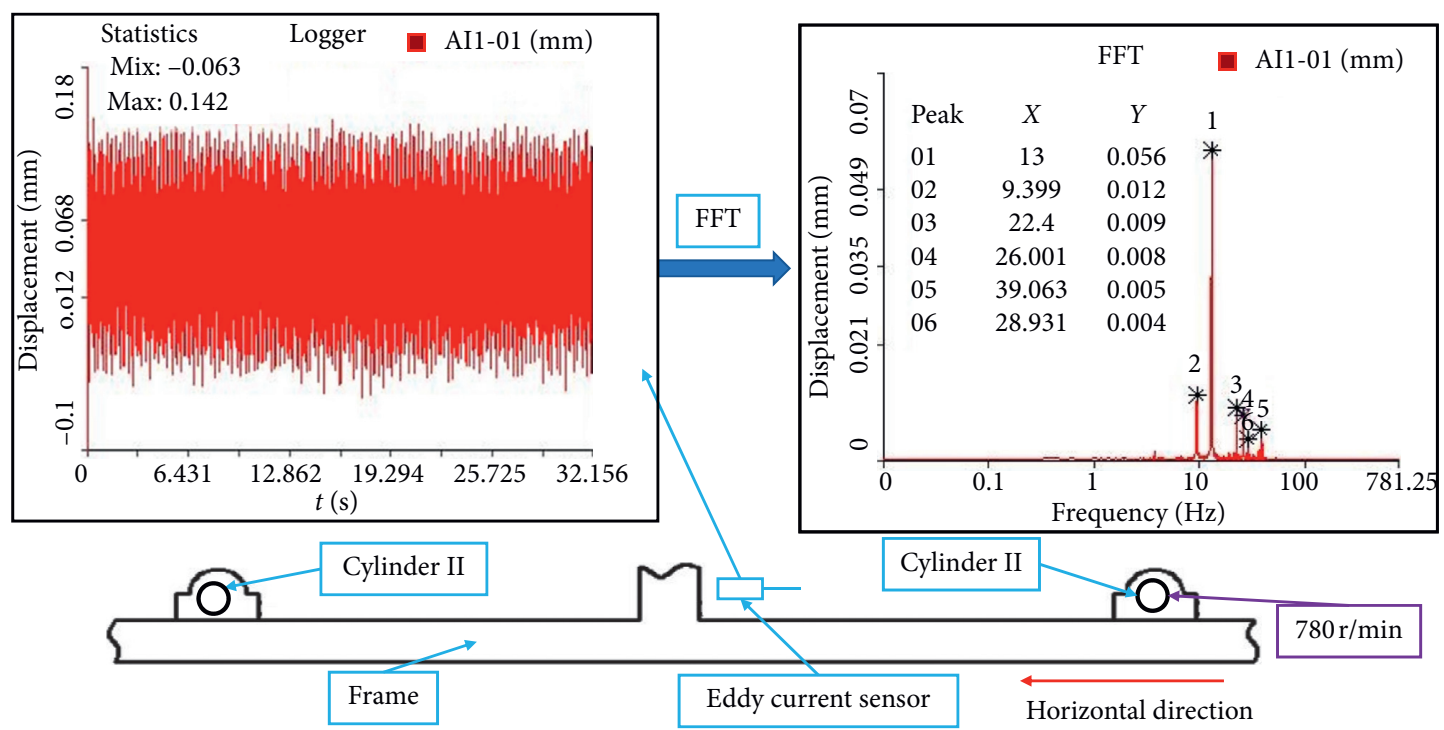

FIgURE 16: Horizontal displacement test result of the frame.

TABle 9: The main data of the time-domain and frequency-domain response of the displacement of the frame.

\begin{tabular}{|c|c|c|c|c|c|c|c|}
\hline \multirow{2}{*}{ Measuring direction } & \multirow{2}{*}{ Main data } & \multicolumn{6}{|c|}{ Rotating speed of motor } \\
\hline & & $600 \mathrm{r} / \mathrm{min}$ & $650 \mathrm{r} / \mathrm{min}$ & $700 \mathrm{r} / \mathrm{min}$ & $750 \mathrm{r} / \mathrm{min}$ & $780 \mathrm{r} / \mathrm{min}$ & $800 \mathrm{r} / \mathrm{min}$ \\
\hline \multirow{5}{*}{ Vertical direction } & Frame displacement (mm) & 0.036 & 0.041 & 0.049 & 0.053 & 0.084 & 0.074 \\
\hline & Frequency $(\mathrm{Hz})$ & 10.01 & 10.803 & 11.658 & 12.512 & 13 & 13.306 \\
\hline & Amplitude (mm) & 0.002 & 0.003 & 0.004 & 0.004 & 0.004 & 0.004 \\
\hline & Frequency $(\mathrm{Hz})$ & 7.202 & 7.813 & 8.362 & 9.033 & 9.399 & 9.583 \\
\hline & Amplitude (mm) & 0.002 & 0.003 & 0.004 & 0.004 & 0.004 & 0.003 \\
\hline \multirow{5}{*}{ Horizontal direction } & Frame displacement $(\mathrm{mm})$ & 0.102 & 0.124 & 0.15 & 0.173 & 0.205 & 0.218 \\
\hline & Frequency $(\mathrm{Hz})$ & 10.01 & 10.803 & 11.658 & 12.512 & 13 & 13.306 \\
\hline & Amplitude (mm) & 0.027 & 0.028 & 0.037 & 0.051 & 0.056 & 0.061 \\
\hline & Frequency $(\mathrm{Hz})$ & 7.202 & 7.813 & 8.362 & 9.033 & 9.399 & 9.583 \\
\hline & Amplitude $(\mathrm{mm})$ & 0.009 & 0.010 & 0.011 & 0.013 & 0.012 & 0.015 \\
\hline \multirow{5}{*}{ Shaft axis } & Frame displacement $(\mathrm{mm})$ & 0.077 & 0.097 & 0.105 & 0.128 & 0.16 & 0.182 \\
\hline & Frequency $(\mathrm{Hz})$ & 10.01 & 10.803 & 11.658 & 12.512 & 13 & 13.306 \\
\hline & Amplitude (mm) & 0.013 & 0.020 & 0.018 & 0.029 & 0.053 & 0.058 \\
\hline & Frequency (Hz) & 14.404 & 21.667 & 14.221 & 14.404 & 9.399 & 13.733 \\
\hline & Amplitude (mm) & 0.004 & 0.004 & 0.003 & 0.004 & 0.004 & 0.004 \\
\hline
\end{tabular}

cylinder itself. For example, when the shape of the axis track of the rotating shaft is an ellipse, it indicates that there is an imbalance on the rotating shaft. With the continuous development and improvement of theory and practice, axis trajectory has become an important means of fault diagnosis for multicylinder system. For a multicylinder system with chain drive as power transmission, the shaft is not only installed on the frame through a supporting device but also connected to adjacent cylinders through a chain drive system. Therefore, in the actual work process, the state of the rotating shaft during the movement may also be affected by the movement state of the transmission chain and the movement state of the adjacent cylinders. In order to analyze the influence of various parts of the system on the movement of the cylinders, the horizontal and vertical displacements of the cylinder shafts under various working conditions were analyzed and processed. Take the data of cylinder I as an example for analysis. Table 10 shows the movement state of the shaft end of cylinder I under each working condition when single/double cylinders were transmitted.

In the actual work process, multiple cylinders are often transmitted in parallel to form a multicylinder chain transmission system. In order to further analyze the influence of the change of the transmission chain and the transmission mode on the system motion state, it was necessary to compare and analyze the test results of the three-cylinder and single/double-cylinder transmission. Table 11 shows the movement state of the shaft end of the cylinder under each working condition of the cylinder I when the three cylinders were driven.

No matter what working state of the cylinder I, its axis track was ellipse, which was caused by the imbalance on the cylinder. In the actual tests, an unbalanced mass with a mass of $227.89 \mathrm{~g}$ was applied to the $120^{\circ}$ phase of the cylinder I, so 
TABLe 10: The movement state of the cylinder I shaft under the transmission of the single/double cylinder.

\begin{tabular}{|c|c|c|c|c|c|c|c|c|}
\hline \multirow{2}{*}{$\begin{array}{l}\text { System transmission } \\
\text { mode }\end{array}$} & \multirow{2}{*}{$\begin{array}{l}\text { Unbalance } \\
\text { of cylinder I }\end{array}$} & \multirow{2}{*}{$\begin{array}{l}\text { Unbalance } \\
\text { of cylinder II }\end{array}$} & \multirow{2}{*}{ Main data } & \multicolumn{5}{|c|}{ Rotating speed of motor } \\
\hline & & & & $600 \mathrm{r} / \mathrm{min}$ & $650 \mathrm{r} / \mathrm{min}$ & $700 \mathrm{r} / \mathrm{min}$ & $750 \mathrm{r} / \mathrm{min}$ & $800 \mathrm{r} / \mathrm{min}$ \\
\hline \multirow{4}{*}{ Single-cylinder transmission } & \multirow{4}{*}{$227.89 \mathrm{~g}$} & \multirow{3}{*}{-} & Horizontal displacement $(\mathrm{mm})$ & 1.532 & 1.517 & 1.505 & 1.489 & 1.425 \\
\hline & & & Vertical displacement (mm) & 1.494 & 1.492 & 1.492 & 1.5 & 1.506 \\
\hline & & & Phase $\left({ }^{\circ}\right)$ & 44.28 & 44.52 & 44.75 & 45.21 & 46.58 \\
\hline & & \multirow{3}{*}{-} & Horizontal displacement $(\mathrm{mm})$ & 1.782 & 1.715 & 1.713 & 1.716 & 1.706 \\
\hline \multirow{8}{*}{ Two-cylinder unilateral transmission } & \multirow[t]{2}{*}{$227.89 \mathrm{~g}$} & & Vertical displacement $(\mathrm{mm})$ & 1.620 & 1.614 & 1.613 & 1.629 & 1.636 \\
\hline & & & Phase $\left({ }^{\circ}\right)$ & 42.27 & 43.26 & 43.27 & 43.51 & 43.80 \\
\hline & \multirow{3}{*}{-} & \multirow{3}{*}{$278.89 \mathrm{~g}$} & Horizontal displacement $(\mathrm{mm})$ & 1.723 & 1.737 & 1.725 & 1.706 & 1.697 \\
\hline & & & Vertical displacement $(\mathrm{mm})$ & 1.607 & 1.609 & 1.622 & 1.618 & 1.617 \\
\hline & & & Phase $\left({ }^{\circ}\right)$ & 43.00 & 42.81 & 43.24 & 43.48 & 43.62 \\
\hline & \multirow{3}{*}{$227.89 \mathrm{~g}$} & \multirow{3}{*}{$278.89 \mathrm{~g}$} & Horizontal displacement $(\mathrm{mm})$ & 1.714 & 1.713 & 1.709 & 1.696 & 1.702 \\
\hline & & & Vertical displacement (mm) & 1.653 & 1.641 & 1.643 & 1.638 & 1.645 \\
\hline & & & Phase $\left({ }^{\circ}\right)$ & 43.96 & 43.77 & 43.87 & 44.00 & 44.02 \\
\hline \multirow{9}{*}{ Two-cylinder bilateral drive } & \multirow{3}{*}{$227.89 \mathrm{~g}$} & \multirow{3}{*}{-} & Horizontal displacement $(\mathrm{mm})$ & 1.634 & 1.601 & 1.599 & 1.590 & 1.583 \\
\hline & & & Vertical displacement $(\mathrm{mm})$ & 1.502 & 1.498 & 1.501 & 1.508 & 1.517 \\
\hline & & & Phase $\left({ }^{\circ}\right)$ & 42.59 & 43.10 & 43.19 & 43.48 & 43.78 \\
\hline & \multirow{3}{*}{ - } & \multirow{3}{*}{$278.89 \mathrm{~g}$} & Horizontal displacement $(\mathrm{mm})$ & 1.659 & 1.656 & 1.667 & 1.676 & 1.679 \\
\hline & & & Vertical displacement $(\mathrm{mm})$ & 1.508 & 1.506 & 1.508 & 1.514 & 1.513 \\
\hline & & & Phase $\left({ }^{\circ}\right)$ & 42.27 & 42.28 & 42.13 & 42.09 & 42.07 \\
\hline & \multirow{3}{*}{$227.89 \mathrm{~g}$} & \multirow{3}{*}{$278.89 \mathrm{~g}$} & Horizontal displacement $(\mathrm{mm})$ & 1.637 & 1.62 & 1.625 & 1.624 & 1.626 \\
\hline & & & Vertical displacement $(\mathrm{mm})$ & 1.505 & 1.502 & 1.508 & 1.518 & 1.518 \\
\hline & & & Phase $\left({ }^{\circ}\right)$ & 42.59 & 42.84 & 42.86 & 43.07 & 43.03 \\
\hline
\end{tabular}

TABLE 11: The movement state of the shaft of the cylinder I under three-cylinder unilateral/bilateral transmission.

\begin{tabular}{|c|c|c|c|c|c|c|c|c|}
\hline \multirow{2}{*}{$\begin{array}{l}\text { System transmission } \\
\text { mode }\end{array}$} & \multirow{2}{*}{$\begin{array}{l}\text { Unbalance } \\
\text { of cylinder I }\end{array}$} & \multirow{2}{*}{$\begin{array}{l}\text { Unbalance } \\
\text { of cylinder II }\end{array}$} & \multirow{2}{*}{ Main data } & \multicolumn{5}{|c|}{ Rotating speed of motor } \\
\hline & & & & $600 \mathrm{r} / \mathrm{min}$ & $650 \mathrm{r} / \mathrm{min}$ & $700 \mathrm{r} / \mathrm{min}$ & $750 \mathrm{r} / \mathrm{min}$ & $800 \mathrm{r} / \mathrm{min}$ \\
\hline \multirow{9}{*}{$\begin{array}{l}\text { Three-cylinder unilateral } \\
\text { transmission }\end{array}$} & \multirow{3}{*}{$227.89 \mathrm{~g}$} & \multirow{3}{*}{-} & $\begin{array}{l}\text { Horizontal displacement } \\
(\mathrm{mm})\end{array}$ & 1.767 & 1.776 & 1.767 & 1.801 & 1.75 \\
\hline & & & Vertical displacement $(\mathrm{mm})$ & 1.607 & 1.625 & 1.616 & 1.623 & 1.642 \\
\hline & & & Phase $\left({ }^{\circ}\right)$ & 43.80 & 42.62 & 42.44 & 42.02 & 43.18 \\
\hline & \multirow{3}{*}{-} & \multirow{3}{*}{$278.89 \mathrm{~g}$} & $\begin{array}{l}\text { Horizontal displacement } \\
(\mathrm{mm})\end{array}$ & 1.731 & 1.723 & 1.712 & 1.764 & 1.738 \\
\hline & & & Vertical displacement $(\mathrm{mm})$ & 1.577 & 1.577 & 1.579 & 1.583 & 1.58 \\
\hline & & & Phase $\left(^{\circ}\right)$ & 42.33 & 42.47 & 42.69 & 41.90 & 42.27 \\
\hline & \multirow{3}{*}{$227.89 \mathrm{~g}$} & \multirow{3}{*}{$278.89 \mathrm{~g}$} & $\begin{array}{c}\text { Horizontal displacement } \\
(\mathrm{mm})\end{array}$ & 1.688 & 1.685 & 1.684 & 1.7 & 1.69 \\
\hline & & & Vertical displacement $(\mathrm{mm})$ & 1.576 & 1.583 & 1.584 & 1.593 & 1.612 \\
\hline & & & Phase $\left(^{\circ}\right)$ & 43.03 & 43.21 & 43.25 & 43.14 & 43.65 \\
\hline \multirow{7}{*}{ Three-cylinder bilateral drive } & \multirow[b]{2}{*}{$227.89 \mathrm{~g}$} & \multirow[b]{2}{*}{-} & $\begin{array}{l}\text { Horizontal displacement } \\
(\mathrm{mm})\end{array}$ & 1.612 & 1.597 & 1.597 & 1.602 & 1.643 \\
\hline & & & $\begin{array}{c}\text { Vertical displacement }(\mathrm{mm}) \\
\text { Phase }\left(^{\circ}\right)\end{array}$ & 1.509 & 1.507 & 1.517 & 1.516 & 1.524 \\
\hline & \multirow{3}{*}{-} & \multirow{3}{*}{$278.89 \mathrm{~g}$} & $\begin{array}{c}\text { Phase }\left(^{\circ}\right) \\
\text { Horizontal displacement } \\
(\mathrm{mm})\end{array}$ & 1.684 & 1.685 & 1.696 & 1.688 & $\begin{array}{l}42.85 \\
1.694\end{array}$ \\
\hline & & & Vertical displacement $(\mathrm{mm})$ & 1.507 & 1.507 & 1.504 & 1.515 & 1.518 \\
\hline & & & Phase $\left(^{\circ}\right)$ & 41.83 & 41.81 & 41.57 & 41.91 & 41.86 \\
\hline & \multirow{2}{*}{$227.89 \mathrm{~g}$} & \multirow{2}{*}{$278.89 \mathrm{~g}$} & $\begin{array}{l}\text { Horizontal displacement } \\
(\mathrm{mm})\end{array}$ & 1.614 & 1.613 & 1.62 & 1.614 & 1.623 \\
\hline & & & Vertical displacement $(\mathrm{mm})$ & 1.509 & 1.51 & 1.514 & 1.522 & 1.527 \\
\hline
\end{tabular}

Note: the phase angle was the angle between the amplitude direction and the horizontal positive direction, and the counterclockwise direction was the positive direction.

the axis track of the rotating shaft was consistent with the actual state. The axis trajectory produced by the imbalance is formed by the superposition of two counter-rotating circles. $e$ diameter of these two circles determines the length of the major axis and minor axis of the ellipse, and the initial phase of the two circles determines the deflection angle $\theta$ of the ellipse. The diameter of the two circles is determined by the stiffness of the system in the horizontal and vertical directions. If the stiffness of the system in all directions is exactly the same, the shape of the axis track is a circle. The initial phase of the two circles is mainly determined by the damping of the system in all directions. The existence of damping makes the vibration of the system produce a phase shift. Take the axis trajectory of cylinder I as an example for analysis, and the result is shown in Figure 17. When the cylinder I rotated alone, the unbalanced vortex form of the response was an ellipse, so there was a certain difference in stiffness between the horizontal and vertical directions. In addition, the existence of damping made the long axis of the ellipse rotate about $45^{\circ}$ around the horizontal axis, so its 


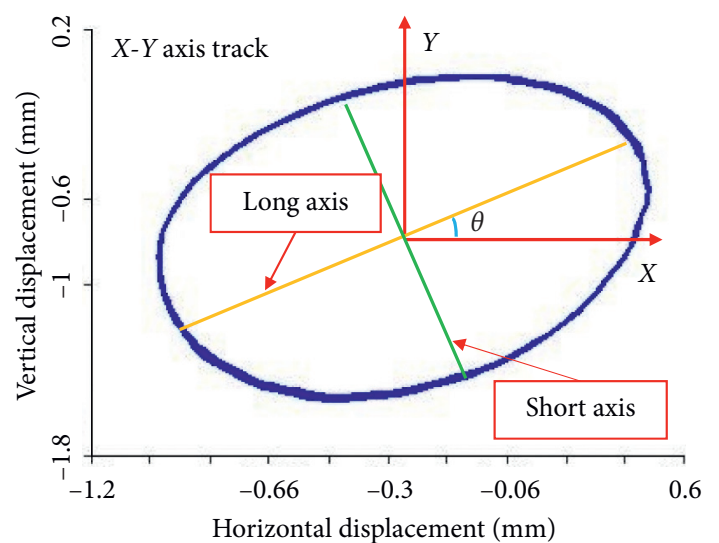

Figure 17: The axis track of the cylinder I.

range of motion in the horizontal and vertical directions was very close.

In the process of power transmission, the shaft and the transmission system were directly connected through a sprocket, so the motion states of the two would affect each other to a certain extent. It can be seen from Tables 10 and 11 that when the drive chain was added to the cylinder, the damping of the cylinder I in the horizontal and vertical directions changed, which changed the state of the shaft. It can be seen that the change of damping would affect the motion state of the shaft. Ferfecki et al. studied the relationship between shaft eccentricity and damping and established a related mathematical model to solve it [35]. The transmission angle of chain transmission was less than $45^{\circ}$, which made its damping in the horizontal direction relatively large, so that the angle of the elliptical axis track under the multicylinder transmission mode was less than $45^{\circ}$. The damping of the transmission chain itself was relatively small, and the transmission method resulted in a difference in the damping of the cylinder in the horizontal and vertical directions, so the deflection angle of the elliptical trajectory was basically between $41.5^{\circ}$ and $45^{\circ}$. It can be seen that the existence of the chain drive would change the damping of the cylinder during work. The specific degree of influence was related to the transmission angle of the chain and the damping produced by the transmission system when transmitting power. In addition, under different working conditions, the length of the long axis and the short axis of the axis trajectory of the cylinder I were also different, so the existence of the transmission chain can also affect the rigidity of the cylinder shaft in all directions. In the multicylinder transmission mode, this trend was more obvious. From the deflection angle of the axis trajectory when the three cylinders were driven, it can be seen that the stiffness and damping difference of the system in all directions became more obvious when the number of chains increased. In particular, the deflection angle of the axis track of cylinder I was quite different from the deflection angle of two-cylinder transmission and single-cylinder transmission.

It can be seen from Tables 10 and 11 that as the rotation speed increased, the deflection angle of the ellipse also increased. The reason for this phenomenon may be the difference in the meshing force of the sprocket during transmission at different speeds. At the same time, the vibration state of the chain was changed, which affected the damping of the cylinder during transmission. Of course, as the rotation speed increased, the vibration produced by the imbalance increased, resulting in a change in the motion state of the rotating shaft, thereby causing a certain change in the length of the long and short shaft trajectory of the rotating shaft. According to the test results, the change in the state of the shaft due to the transmission mode and motion state was relatively small, and the motion state of the cylinder shaft was mainly determined by the inherent properties of the system.

As the various parts of the multicylinder system were closely connected, the entire system was coupled with each other, resulting in extremely complex vibration influence relationships of the entire system. Due to the existence of the transmission chain and the frame, the motion state of adjacent rotating shafts may influence each other through the frame and the transmission chain. Therefore, in order to analyze the influence of the transmission chain on the vibration response of the rotating shaft, it was necessary to analyze the displacement response of the rotating shaft. The displacement signal in the main direction of the shaft vibration was subjected to FFT transformation to analyze the frequency components of the shaft vibration, thereby analyzing the transmission characteristics of the transmission chain vibration. Take the movement state of the rotating shaft when the two-cylinder was transmitted unilaterally as an example for analysis. The displacement signal when the rotating speed of motor was $800 \mathrm{r} / \mathrm{min}$ was transformed by FFT, and the result is shown in Figure 18.

Since the frequency components of the shaft displacement were mainly concentrated in the low-frequency part, the abscissa was changed to logarithmic coordinates for display. It can be seen from the FFT result that the main frequency component of the displacement of the shaft in the horizontal and vertical directions was the fundamental frequency of the cylinder. In the multicylinder system, only the rotating frequency of the cylinder I and the motor was the same as this frequency. Therefore, the main reason for the vibration of the rotating shaft may be the imbalance of the cylinder itself, which was shown in the shape of the shaft track, but the influence of the motor vibration in this process cannot be ruled out. In addition, there was the frequency of the adjacent cylinders in the horizontal displacement frequency of the rotating shaft. This frequency may be transmitted to the rotating shaft through the frame or through the transmission chain. The actual condition was that the frequency spectrum of the displacement signal of the shaft showed that the amount of vibration in the high-frequency part was very small. Therefore, the vibration of adjacent cylinders was mainly transmitted through the frame.

In addition, it was found in the experiment that the increase of the transmission chain may cause the installation state of the shaft to change. Take the axis trajectory of cylinder II under three-cylinder unilateral transmission and two-cylinder bilateral transmission as an example. The results under the same working condition are compared and analyzed, and the corresponding axis trajectory is shown in Figure 19. 


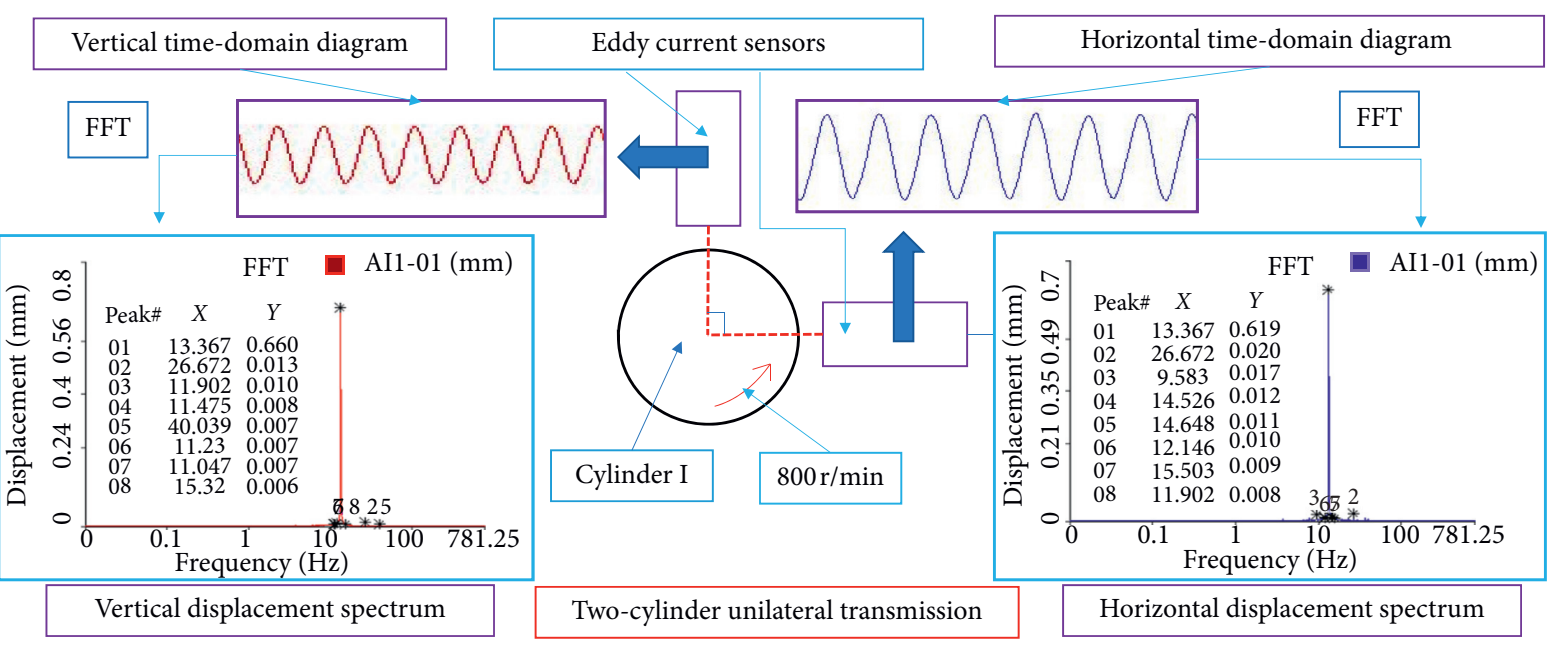

FIgURE 18: FFT of horizontal and vertical displacement.
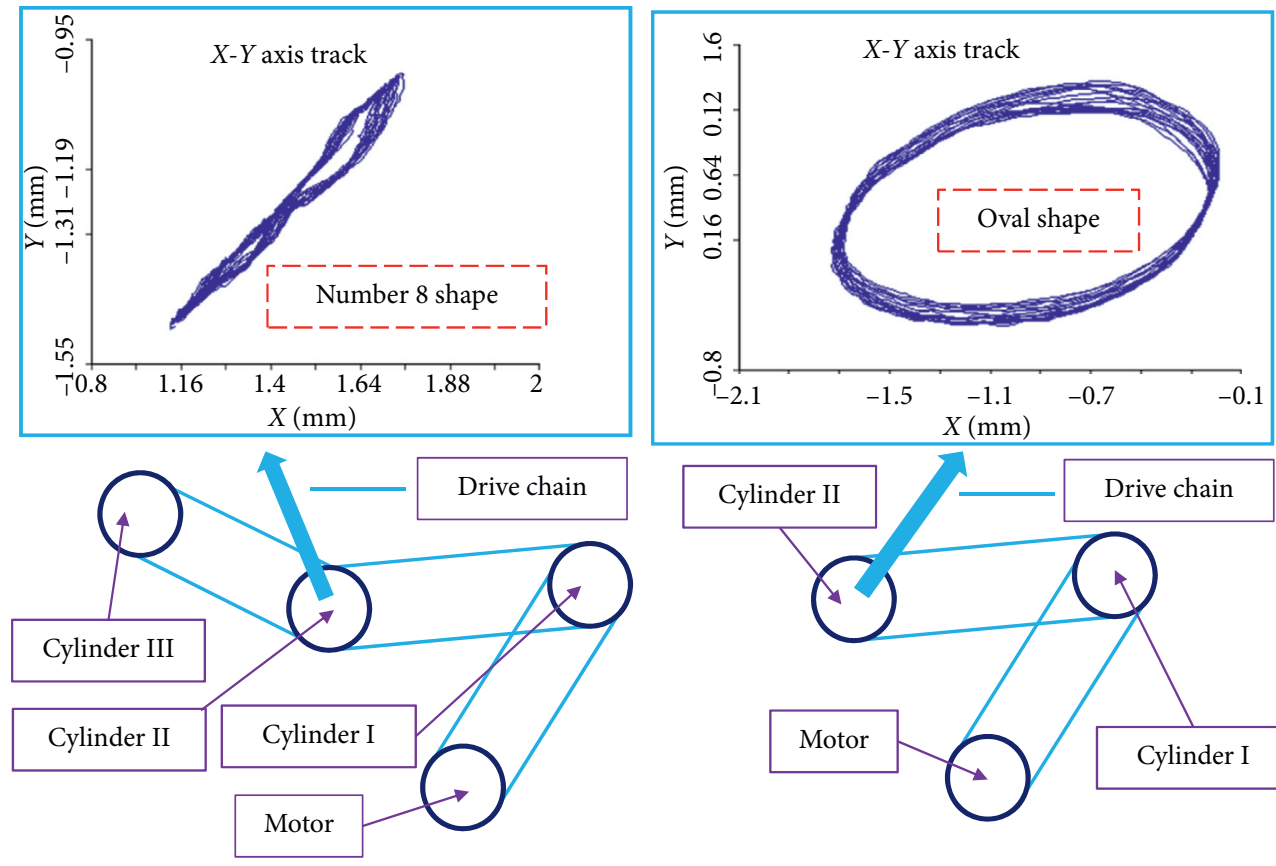

Three-cylinder unilateral transmission

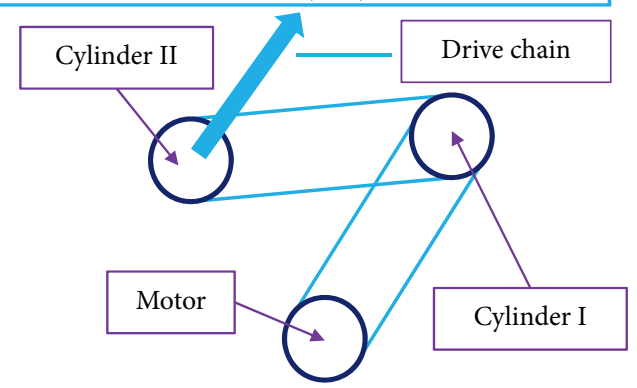

Two-cylinder unilateral transmission

FIGURE 19: Cylinder II axis track under different working conditions.

As shown in Figure 19, the axis track of the cylinder II was an ellipse before the drive chain was applied. The main reason for this phenomenon was the imbalance of the cylinder. When the transmission chain was added, its axis trajectory changed to a figure of eight, which showed that the shaft was misaligned due to the increase of the transmission chain. In this state, the double-frequency component of the cylinder was large, which would cause the rotating bearing to be periodically forced to vibrate causing the rotating shaft to be prone to fatigue damage and shorten the service life. Therefore, it was necessary to pay special attention to such situations during the actual installation of the transmission chain, so as to improve the working reliability and service life of the system.

\section{Conclusions}

(1) Through the vibration characteristic tests of the bearing seat position under different transmission modes, it was known that the degree of influence under different transmission modes and speeds was different. In general, its influence on the vibration of the cylinder at the fundamental frequency was $5 \%$ $30 \%$. The change in the vibration response was mainly due to the existence of the transmission chain and the change in the transmission mode, which changed the boundary conditions of the system. Since the vibration response of each cylinder would be transmitted to each other, the vibration 
component of the bearing seat position was very complicated. In addition to the vibration produced by its own rotation, the vibration component of the bearing seat mainly included the vibration of the transmission chain, the vibration generated by the unbalanced response of the cylinder, and the vibration generated by the rotation of the motor. The meshing impact of the chain drive in the transmission process was the frequency component that caused the largest vibration impact energy at the bearing seat. As the unbalanced mass on the cylinder increased, the vibration response caused by the unbalance of the cylinder became the main part of the vibration component of the bearing seat.

(2) Through the analysis of the vibration characteristics and transmission characteristics of the multicylinder transmission frame, it was known that the frame was the main medium of vibration transmission in the entire system, and its vibration transmission efficiency at different frequencies can reach more than $80 \%$. The transmission characteristics of the frame were closely related to its stiffness, and the difference in stiffness at different positions had a significant impact on the coupling effect of the frame. The unbalanced response of each cylinder was transmitted to each bearing seat position in the system through the frame, and the vibration generated by the rotation of the motor was also transmitted to each position of the system through the frame. Through the analysis of the vibration response of each excitation source on the frame, it can be obtained that the vibration of the frame was mainly caused by the rotation of the motor, followed by the vibration response caused by the imbalance on cylinders. The vibration generated by the chain drive had least influence on the vibration response of the frame.

(3) It was known that the change of the transmission chain and the transmission mode influenced the stiffness and damping of the system, resulting in a change of $1^{\circ} \sim 5^{\circ}$ in the deflection angle of the axis trajectory of the rotating shaft under different transmission modes. Through the analysis of the vibration response of the rotating shaft, it was known that the state of the rotating shaft was mainly determined by the magnitude and phase of the imbalance on the cylinder. Other excitation sources had a certain influence on its vibration state, but the magnitude of the influence did not exceed $10 \%$. The existence of the transmission chain would also change the installation state of the cylinder shaft, resulting in deviations in the installation. As a result, the rotating shaft was prone to fatigue damage and shortened service life.

\section{Data Availability}

The data used to support the findings of this study are available from the corresponding author upon request.

\section{Conflicts of Interest}

The authors declare that they have no conflicts of interest.

\section{Acknowledgments}

This research work was supported by the National Key Research and Development Project (2017YFD0700203), Jiangsu Province Postgraduate Research and Innovation Project (KYCX20_3086), and National Natural Science Foundation of China (51705212).

\section{References}

[1] Z. Tang, Y. Li, X. Li, and T. Xu, "Structural damage modes for rice stalks undergoing threshing," Biosystems Engineering, vol. 186, pp. 323-336, 2019.

[2] Z. Tang, Y. M. Li, and C. Cheng, "Development of multifunctional combine harvester with grain harvesting and straw baling," Spanish Journal of Agricultural Research, vol. 15, no. 1, Article ID e0202, 2017.

[3] Z. Tang, Y. M. Li, and Z. Zhao, "Structural and parameter design of transverse multi-cylinders device on rice agronomic characteristics," Spanish Journal of Agricultural Research, vol. 13, no. 4, Article ID e0216, 2015.

[4] Z. Tang, H. T. Zhang, H. Zhang et al., "Developments of crawler steering gearbox for combine harvester straight forward and steering in situ," International Journal of Agricultural and Biological Engineering, vol. 13, no. 1, pp. 120-126, 2020.

[5] Z. Tang, H. T. Zhang, and Y. P. Zhou, "Unbalanced vibration identification of tangential threshing cylinder induced by rice threshing process," Shock and Vibration, vol. 2018, Article ID 4708730, 14 pages, 2018.

[6] Z. Tang, X. Li, X. Liu, H. Ren, and B. Zhang, "Dynamic balance method for grading the chain drive double threshing drum of a combine harvester," Applied Sciences, vol. 10, no. 3, pp. 1026-1046, 2020.

[7] Z. Tang, M. Wang, H. Zhang, Y. Zhou, and Y. Li, "Variation and modal characteristic of tangential threshing cylinder undergoing threshing dynamics," Mathematical Problems in Engineering, vol. 2020, Article ID 1723893, 15 pages, 2020.

[8] G. Čepon and M. Boltežar, "Dynamics of a belt-drive system using a linear complementarity problem for the belt-pulley contact description," Journal of Sound and Vibration, vol. 319, no. 3-5, pp. 1019-1035, 2009.

[9] G. Čepon, L. Manin, and M. Boltežar, "Introduction of damping into the flexible multibody belt-drive model: a numerical and experimental investigation," Journal of Sound and Vibration, vol. 324, no. 1-2, pp. 283-296, 2009.

[10] A. Ward and R. S. Dwyer-Joyce, "Model experiments on automotive chain drive systems," Tribology Series, vol. 39, pp. 851-861, 2001.

[11] O. A. Assad, E. Godoy, and V. Croulard, "Macroscopic drive chain efficiency modeling using state machines," IFAC Proceedings Volumes, vol. 41, pp. 2294-2299, 2008.

[12] Y. Wang, D. Ji, and K. Zhan, "Modified sprocket tooth profile of roller chain drives," Mechanism and Machine Theory, vol. 70, pp. 380-393, 2013.

[13] C. Pereira, J. Ambrósio, and A. Ramalho, "Dynamics of chain drives using a generalized revolute clearance joint formulation," Mechanism and Machine Theory, vol. 92, pp. 64-85, 2015. 
[14] N. Fuglede and J. J. Thomsen, "Kinematics of roller chain drives-exact and approximate analysis," Mechanism and Machine Theory, vol. 100, pp. 17-32, 2016.

[15] N. Fuglede and J. J. Thomsen, "Kinematic and dynamic modeling and approximate analysis of a roller chain drive," Journal of Sound and Vibration, vol. 366, pp. 447-470, 2016.

[16] H. Zhang, J. Zhai, Q. Han, and W. Sun, "Dynamics of a geared parallel-rotor system subjected to changing oil-bearing stiffness due to external loads," Finite Elements in Analysis and Design, vol. 106, pp. 32-40, 2015.

[17] Y. Yu, L. Zhao, and C. Zhou, "Influence of rotor-bearing coupling vibration on dynamic behavior of electric vehicle driven by In-wheel motor," IEEE Access, vol. 7, pp. 6354063549, 2019.

[18] L. Xiang and N. Gao, "Coupled torsion-bending dynamic analysis of gear-rotor-bearing system with eccentricity fluctuation," Applied Mathematical Modelling, vol. 50, pp. 569584, 2017.

[19] A. Saxena, M. Chouksey, and A. Parey, "Measurement of FRFs of coupled geared rotor system and the development of an accurate finite element model," Mechanism and Machine Theory, vol. 123, pp. 66-75, 2018.

[20] T.-Z. Yang, B. Fang, Y. Chen, and Y.-X. Zhen, “Approximate solutions of axially moving viscoelastic beams subject to multi-frequency excitations," International Journal of NonLinear Mechanics, vol. 44, no. 2, pp. 230-238, 2009.

[21] S. Wang, A. Xieeryazidan, X. Zhang, and J. Zhou, "An improved computational method for vibration response and radiation noise analysis of two-stage gearbox," IEEE Access, vol. 8, pp. 85973-85988, 2020.

[22] Y. Briend, M. Dakel, E. Chatelet, M. Andrianoely, R. Dufour, and S. Baudin, "Effect of multi-frequency parametric excitations on the dynamics of on-board rotor-bearing systems," Mechanism and Machine Theory, vol. 145, Article ID 103660, 2020.

[23] Y. Yang, C. Liu, and D. Jiang, "Vibration propagation identification of rotor-bearing-casing system using spatiotemporal graphical modeling," Mechanism and Machine Theory, vol. 134, pp. 24-38, 2019.

[24] D. Wu, T. Xie, M. Lu et al., "Modeling and experimental study on the micro-vibration transmission of a control moment gyro," IEEE Access, vol. 7, pp. 80633-80643, 2019.

[25] L. Hou, S. Cao, T. Gao, and S. Wang, "Vibration signal model of an aero-engine rotor-casing system with a transfer path effect and rubbing," Measurement, vol. 141, pp. 429-441, 2019.

[26] Z. Zeng, K. Ding, G. He, and W. Li, "Space-time model and spectrum mechanism on vibration signal for planetary gear drive," Mechanical Systems and Signal Processing, vol. 129, pp. 164-185, 2019.

[27] S. He, T. Tang, M. Ye, E. Xu, and Z. Jiang, "A multi-point iterative analysis method for vibration control of a steering wheel at idle speed," IEEE Access, vol. 7, pp. 88399-88417, 2019.

[28] S. Chen, Y. Zhou, Z. Tang, and S. Lu, "Modal vibration response of rice combine harvester frame under multi-source excitation," Biosystems Engineering, vol. 194, pp. 177-195, 2020.

[29] Z. Tang, Y. M. Li, and J. B. Liu, "Dynamic vibration test and analysis of $4 \mathrm{LZ}-2.5 \mathrm{~B}$ combine harvester cutting table rack in wheat harvesting," International Agricultural Engineering Journal, vol. 26, no. 1, pp. 79-86, 2017.

[30] Z. Y. Xie, Q. D. Zhou, and Y. C. Pan, "Simulation and tests for vibration of structures under multi-point complex loads,"
Journal of Vibration and Shock, vol. 37, no. 11, pp. 166-174, 2018.

[31] Z. Tang, X. Y. Li, X. D. Chen, and Y. Chen, "Design of negative pressure spiral feeding device for tangential and longitudinal axial intersection of combine harvester," Advances in Materials Science and Engineering, vol. 2019, Article ID 7610767, 12 pages, 2019.

[32] F. K. Choy, Y. F. Ruan, J. Zakrajsek, and F. B. Oswald, "Modal simulation of gear box vibration with experimental correlation," Journal of Propulsion and Power, vol. 9, no. 2, pp. 301-306, 1993.

[33] L. Xu, X. Y. Chai, X. Chai, Z. Gao, Y. Li, and Y. Wang, "Experimental study on driver seat vibration characteristics of crawler-type combine harvester," International Journal of Agricultural and Biological Engineering, vol. 12, no. 2, pp. 90-97, 2019.

[34] J. Pang, Y. M. Li, X. Jin, and L. Z. Xu, "Detection and analysis of typical vibration load of grain harvester based on shorttime Fourier method," The International Journal of Electrical Engineering \& Education, vol. 2019, p. 8, 2019.

[35] P. Ferfecki, J. Zapoměl, and J. Kozánek, "Analysis of the vibration attenuation of rotors supported by magnetorheological squeeze film dampers as a multiphysical finite element problem," Advances in Engineering Software, vol. 104, pp. 1-11, 2017. 